\title{
Multianvil techniques in conjunction with synchrotron radiation at Deutsches ElektronenSYnchrotron (DESY) - HAmburger SYnchrotron LABor (HASYLAB)
}

\author{
Hans J. Mueller ${ }^{\dagger}$ \\ Frank R. Schilling \\ Christian Lathe \\ GeoForschungsZentrum Potsdam in der Helmholtz-Gemeinschaft, Department 5, D-14473 Potsdam, Germany
}

\begin{abstract}
During the early 1980s, geoscientists worldwide realized synchrotron radiation was a highly valuable tool for in situ experiments, i.e., experiments under simulated Earth mantle conditions. MAX80 at Deutsches ElektronenSYnchrotron (DESY) - HAmburger SYnchrotron LABor (HASYLAB), Hamburg, a single-stage multianvil DIA system at a synchrotron beam line was among the high-pressure pioneer apparatus designed in Japan. MAX80 is equipped to perform ultrasonic interferometry in conjunction with synchrotron radiation measurements, i.e., $\mathrm{X}$-ray diffraction $(\mathrm{XRD})$ and $\mathrm{X}$-radiography. The maximum conditions are $\sim 12 \mathrm{GPa}$ at $2000 \mathrm{~K}$.

To make transition-zone conditions accessible and to achieve bigger specimen volumes, the sister apparatus MAX200x, a double-stage DIA system, was recently installed at the HASYLAB HARWI-II beam line. MAX2000x is designed to reach $25 \mathrm{GPa}$ and $2400 \mathrm{~K}$, simultaneously. MAX200x is driven by a hydraulic ram with a maximum load of 1750 tons. Derived from the successful equipment of MAX80 and adapted to the new task, MAX200x is equipped for XRD with a Ge-solid-state detector, for transient ultrasonic interferometry, and it has a radiography system to measure change of volume and shape of the sample under in situ conditions. A stepper motor-driven slits system allows the $\mathrm{X}$-ray beam size and shape to be optimized for experiments.

Parallel to the installation of MAX200x, some experiments were carried out to improve the potentials of multianvil apparatus in terms of maximum pressure and limitation of stress inside the sample and the anvils. Some recent results of these experiments as well as the data from the first experiments with the new double-stage system are reported here.
\end{abstract}

Keywords: multianvil high-pressure cell, DIA, ultrasonic interferometry, ultrasonic data transfer function, XRD, X-radiography, quartz to coesite transition, clinoenstatite.

†E-mails: hjmuel@gfz-potsdam.de; hans-joachim.mueller@gfz-potsdam.de.

Mueller, H.J., Schilling, F.R., and Lathe, C., 2007, Multianvil techniques in conjunction with synchrotron radiation at Deutsches ElektronenSYnchrotron (DESY) - HAmburger SYnchrotron LABor (HASYLAB), in Ohtani, E., ed., Advances in High-Pressure Mineralogy: Geological Society of America Special Paper 421, p. 207-226, doi: 10.1130/2007.2421(12). For permission to copy, contact editing@geosociety.org. (C2007 Geological Society of America. All rights reserved. 


\section{INTRODUCTION}

In 1969, the first human put his foot on the surface of the moon. Now $35 \mathrm{yr}$ later, mankind is going to fly to our outer neighbor planet-Mars. Geoscience and planetary science approach each other more and more. Satellite-based Earth observation has become indispensable for geoscience. Probably, in the not too distant future, we will record detailed seismic data from planets and planetary bodies. To interpret them and to compare them with existing terrestrial data will be a tremendous challenge and the biggest opportunity geoscience ever had at the same time. But we have to realize that our current understanding of the ongoing dynamic processes deep inside our home planet is still quite limited.

In situ studies of Earth's materials are the necessary complement to the progress of global seismology in general and of the tomographic method in particular. Understanding and modeling of mantle dynamics require more detailed insights into the structural and physical properties of materials relevant for great depths. Ultradeep subduction, penetrating into the lower mantle, and the interpretation of slab recycling in plumes require a fundamental understanding of the water and energy budget of our planet Earth (Bolfan-Casanova et al., 1997, 1998, 2002; Kohlstedt, 1994a, 1994b, 1996; Kohlstedt et al., 1994, 1996; Litasov et al., 2003, 2004; Litasov and Ohtani, 2003a, 2003b, 2005; Ohtani and Maeda, 2001; Ohtani et al., 2000, 2001a, 2001b, 2003, 2004; Rubie and Ross-II, 1994; Rubie et al., 1990; Suzuki et al., 2001). Following this line, the transition zone and the core-mantle boundary are regions of special interest. To face this scientific challenge, we have to improve and develop in situ high-pressure tools and techniques. By combining structural examinations and measurements of physical properties, e.g., elastic constants, large-volume presses can significantly enhance precision. To enhance the pressure range of multianvil apparatus, new materials are required, e.g., polycrystalline diamond with ceramic binder, big synthetic single-crystal diamonds grown from the gas phase, composite materials using carbon fiber. New techniques, e.g., high brilliance X-ray and high-intensity neutron sources, 3-D simulation software, and methods for transient measurements in mineral physics, significantly improve the potentials of this high-pressure technique, and they are available now or will be in the near future. High-pressure technology seems to be on the way to becoming a key technology for geosciences, material sciences, physics, and chemistry.

\section{EXPERIMENTAL TECHNIQUES}

\section{Single-Stage Multianvil MAX80}

\section{Pressure Generation}

MAX80 consists of a $2500 \mathrm{~N}$ hydraulic ram and two load frames that drive four reaction bolsters for the lateral anvils (Fig. 1). The lateral bolsters together with the top and bottom ones push six tungsten carbide (TC) anvils, which can compress a cubic sample volume of 512-216 $\mathrm{mm}^{3}$ (Mueller et al., 2005b). The total weight is $\sim 1.5$ tons. The original MAX80 was a Japanese design (Shimomura et al., 1984, 1985; Liebermann et al., 1985; Yagi et al., 1987a, 1987b; Yagi, 1988). It started opera-

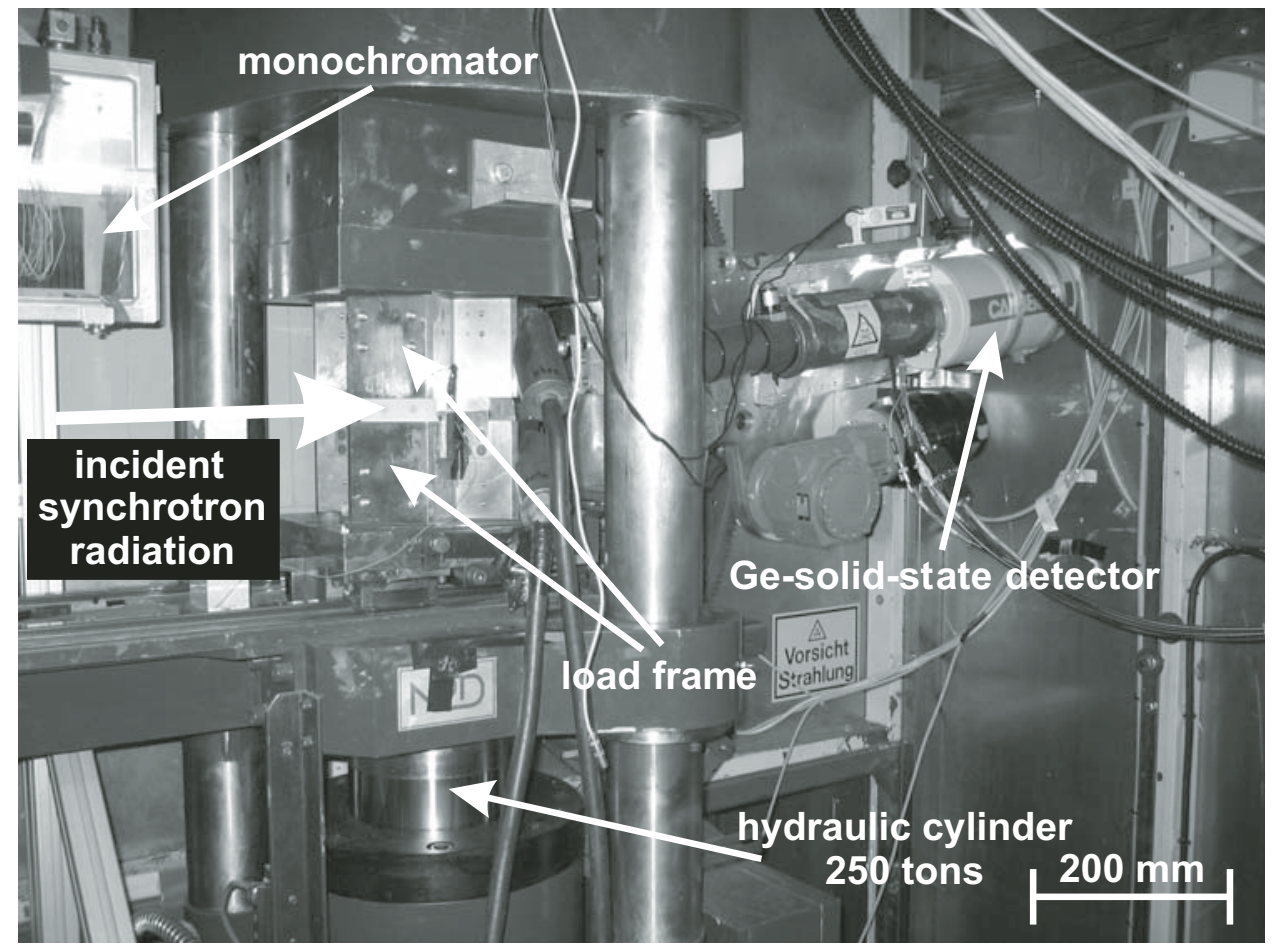

Figure 1. MAX80 showing load frame, Ge-solid-state detector, and monochromator (not in working position); white synchrotron radiation is used. The bottom hydraulic cylinder pushes the bottom anvil against the top anvil. At the same time, both load frames push the four lateral anvils toward the central boron epoxy cube. The incident synchrotron beam is guided through the gaps between the tungsten carbide anvils to the sample. The Ge-solid-state detector records the diffracted beam at a fixed angle. For angle-dispersive X-ray diffraction (XRD), a double-crystal, fixed-offset monochromator with silicon (311) single crystals can be moved to the white synchrotron beam. 
tions at the Photon Factory, the synchrotron radiation laboratory at the National Laboratory for High-Energy Physics in Tsukuba, Japan. MAX80 stands for multiAnvil-type high-pressure X-ray system. It was designed to obtain powder diffraction patterns using the energy-dispersive technique under high-pressure and high-temperature conditions. Shortly after the original press, a similar sister apparatus was installed in Europe in 1991 at HASYLAB (HAmburger SYnchrotron LABoratory) at DESY (Deutsches ElektronenSYnchrotron), Hamburg, Germany (Hinze et al., 1991, 1992). Today MAX80 at HASYLAB is operated by GeoForschungsZentrum Potsdam. Other similar apparatuses, with slight modifications, have come into use worldwide.

The press operated at beam-line F2.1 at HASYLAB, DESY, is equipped with three anvil sets with different truncations: $6 \mathrm{~mm}, 4 \mathrm{~mm}$, and $3.5 \mathrm{~mm}$. The maximum attainable pressures using the tungsten carbide anvils with the smallest front face reach $12 \mathrm{GPa}$ at $2000 \mathrm{~K}$ produced by an internal graphite heater. The biggest truncation limits the maximum pressure to $\sim 7 \mathrm{GPa}$. To enhance the lifetime of the anvils, we usually use cubic boron nitride anvils instead of the classical tungsten carbide anvils (Mueller et al., 2002). Use of sintered diamond anvils as second stage in similar-sized multianvil apparatus (MA8 type apparatus MAX80, MAX90) results in maximum pressures of more than $30 \mathrm{GPa}$ (Utsumi et al., 1992; Shimomura et al., 1992; Kondo et al., 1993a, 1993b; Funamori et al., 1996). Recent studies using the stronger DIA-type press SPEED MkII (Katsura et al., 2004) at SPring-8, Japan, have reached $63 \mathrm{GPa}$ with a load of $\sim 10,000 \mathrm{kN}$ (Ito et al., 2005).

Compression of the boron epoxy cubes results in a nearly hydrostatic (quasi-hydrostatic) pressure at the center. Depending on the given load, some part of the cubes floats out between the gaps of the anvils forming the gaskets (Fig. 2). This common technique is simple for the user, but it results in high lateral tension in the outer parts of the cube accompanied by strong plastic deformation, and it limits the "survival" of the anvils and the maximum pressure.

Prefabricated gasket insets are one way to increase the lateral anvil support at the expense of pressure efficiency, i.e., the relation between applied ram load and resulting pressure. We successfully used gasket strips made from Klinger SIL C-4400, an industrial sealing material made from NBR (Nitrile Butadiene Rubber) tied p-aramide fibers, for tungsten carbide and cubic boron nitride anvils. The experiments demonstrated that maximum pressures at least $25 \%$ higher compared to the standard MAX80 configuration are easily achievable while using prefabricated gaskets. Further benefits are a reduced number of blowouts, i.e., decompression of the cell assembly by gasket failure, and higher X-ray intensity at peak pressures due to the larger gap width between the anvils (Mueller et al., 2005a).

\section{$X$-Ray Diffraction (XRD)}

Beam-line F2.1 is a bending magnet beam line at the storage ring DORIS III (DOuble RIng Storage) that has a circumference of $300 \mathrm{~m}$, converted to a pure synchrotron in 1993. It works with a maximum energy of $4.5 \mathrm{GeV}$ in five bunch mode for $\sim 500 \mathrm{~h} / \mathrm{yr}$. DORIS III works in two bunch mode $20 \%$ of the time.

Most of the experiments are carried out using energydispersive X-ray diffraction. The synchrotron beam is guided between the tungsten carbide anvils through the sample. A Ge-solid-state detector (resolution: $135 \mathrm{eV}$ for $6.3 \mathrm{keV}$ and $450 \mathrm{eV}$ for $122 \mathrm{keV}$ ) records the diffracted beam at a fixed angle. The maximum available $2 \theta$ range is $30^{\circ}$. MAX80 can be adjusted in three directions: (1) vertically to focus the X-ray beam on different parts of the setup, e.g., specimen and pressure standard

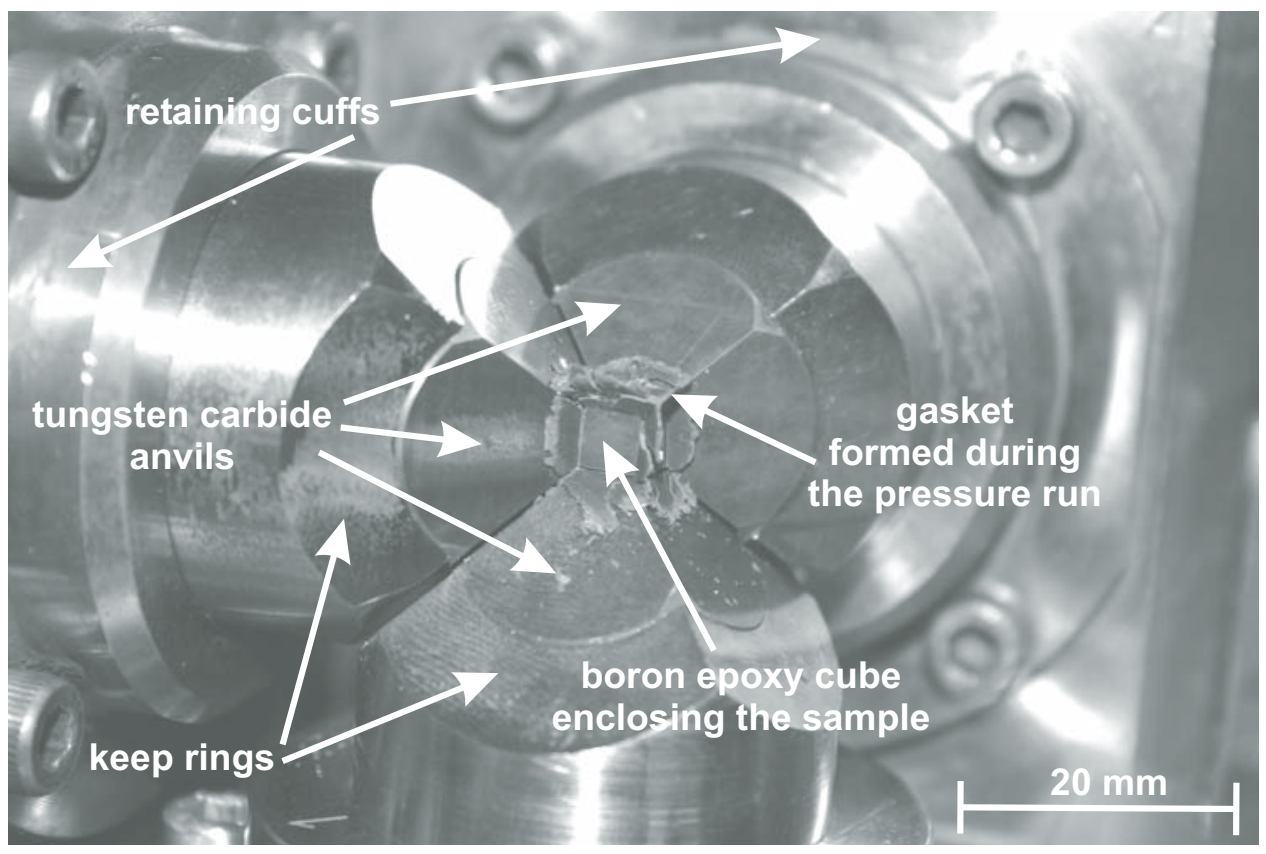

Figure 2. MAX80 showing boron epoxy cube with gaskets after a high-pressure run. Two lateral anvils and the top anvil have already been removed after the high-pressure run. Due to the load of high confining pressure, part of the boron epoxy cube flows into the gaps between the anvils forming gaskets. The gaskets "seal" the volume under pressure. 
as well as to compensate for the pressure-induced deformation; (2) horizontally, perpendicular to the synchrotron beam, to adjust the synchrotron beam to the slots between the tungsten carbide anvils with an accuracy of $10 \mu \mathrm{m}$ using stepper motors; and (3) the stepper motor-driven rotational table allows adjustment of the opposite-facing slots between the anvils parallel to the synchrotron beam with an accuracy of $0.01^{\circ}$. The diffractometer is linked with the high-pressure apparatus and has four degrees of freedom: (1) rotation around the vertical axis of the sample, (2) horizontal translation perpendicular to the beam, (3) vertical translation, and (4) $2 \theta$ rotation of the detector. The primary beam size and the diffracted beam size are limited by stepper motordriven crossed-slit systems to $50 \times 50 \mu \mathrm{m}$ and $500 \times 500 \mu \mathrm{m}$, respectively. Energy-dispersive X-ray diffraction may also be performed to measure the pressure inside the boron epoxy cube using the high-pressure equation of state for $\mathrm{NaCl}$ (Decker, 1971). All pressure measurements during the experiments described in this paper were performed this way.

For angle-dispersive X-ray diffraction, a double-crystal, fixed-offset monochromator with silicon (311) single crystals is installed additionally, in order to get higher resolution and to allow structure refinements under in situ conditions. The monochromator is calibrated in the wavelength range between 0.4 and $0.6 \AA$. For online data acquisition, a Stoe linear position sensitive detector ( $7^{\circ}$ at $15 \mathrm{~cm}$ distance) is available. The detector is equipped with a conical slit system. Further progress concerning the resolution could be reached by using the imaging plate.

\section{X-Radiography}

$\mathrm{X}$-radiography allows us to measure variations of sample length at high pressure-temperature $(P-T)$ conditions ( $\mathrm{Li}$ et al., 2001). It is a prerequisite for ultrasonic experiments to determine elastic properties. Viscosity measurement of melts by the falling sphere method is a further application for X-radiography under high-pressure conditions (Tinker et al., 2004).

To establish an X-radiography system at MAX80, the original fixed double-slit unit was exchanged with a four-blade highprecision slit system of Advanced Design Consulting USA, Inc. (ADC). The maximum slit opening is 1 inch. The motion reproducibility is $1 \mu \mathrm{m}$ with a motion resolution of $0.4 \mu \mathrm{m}$ remote controlled by a computer. Because the four blades can be moved independently from each other, the slits system is not only able to control the beam size, but it can also define the X-ray beam position. For X-radiography, the blades are opened far enough that the X-ray beam covers the whole sample length, including a part of the adjacent buffer and reflector rods. Using anvils absorbing the synchrotron radiation, e.g., made from tungsten carbide, the maximum horizontal opening of the beam is adapted to the maximum available gap between the lateral anvils, $\sim 1.5 \mathrm{~mm}$ at normal pressure and $<0.5 \mathrm{~mm}$ at maximum pressure conditions to limit the scattered radiation inside the hutch and to enhance the resolution of the diffraction patterns.

After penetrating the high-pressure cell assembly, the $\mathrm{X}$-ray shadow graph is partially converted by fluorescence of a 0.1-mm-thick Ce: YAG (Cerium doped Yttrium Aluminum Garnet) crystal ([by courtesy of IKZ (Institut für Kristallzüchtung)]) to an optical image of $\sim 540 \mathrm{~nm}$ wavelength (green). An aluminum-coated mirror decouples the optical from the nonconverted X-ray image, which is absorbed in the beam-stop (Figs. 3 and 4). Otherwise the intense X-rays would destroy the CCD (Charge-Coupled Device) chip of the camera and would cause radiation damage in the optical glass of the lenses. The limit of the optical resolution is determined by the wavelength of green light of $\sim 0.5 \mu \mathrm{m}$ and the aperture of the objective of less than 0.5 to a total of $\sim 1 \mu \mathrm{m}$ (Mueller et al., 2005a). The minimum object distance is a strongly limiting factor for the

\section{4-blade high-precision} slits system

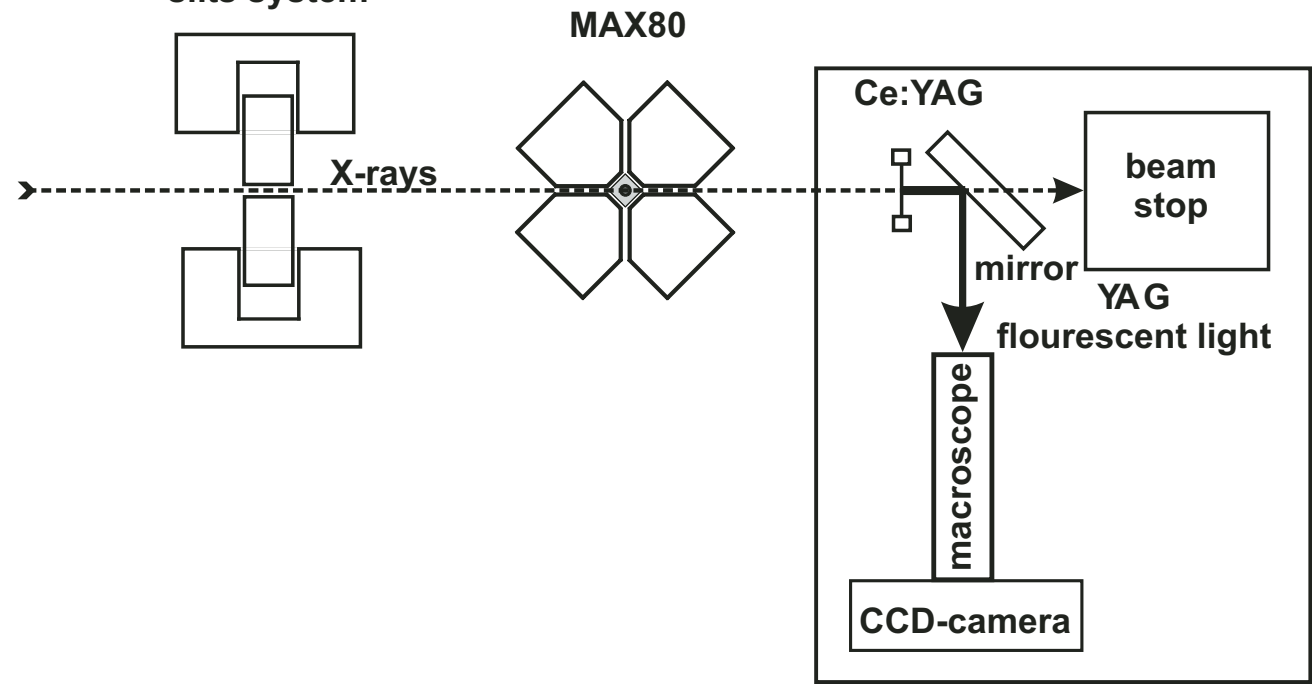

Figure 3. Scheme of X-radiography. The slits system shapes the incident synchrotron beam to a size slightly larger than the sample dimensions. After passing the sample inside MAX80, an X-ray shadow graph of the sample is projected on the Ce: YAG (Cerium doped Yttrium Aluminum Garnet) crystal. It converts the X-ray image to a visible one by fluorescence. The mirror redirects this optical image to a microscope with a CCD (Charge-Coupled Device) camera. The direct $X$-ray beam is absorbed by the beam stop. 


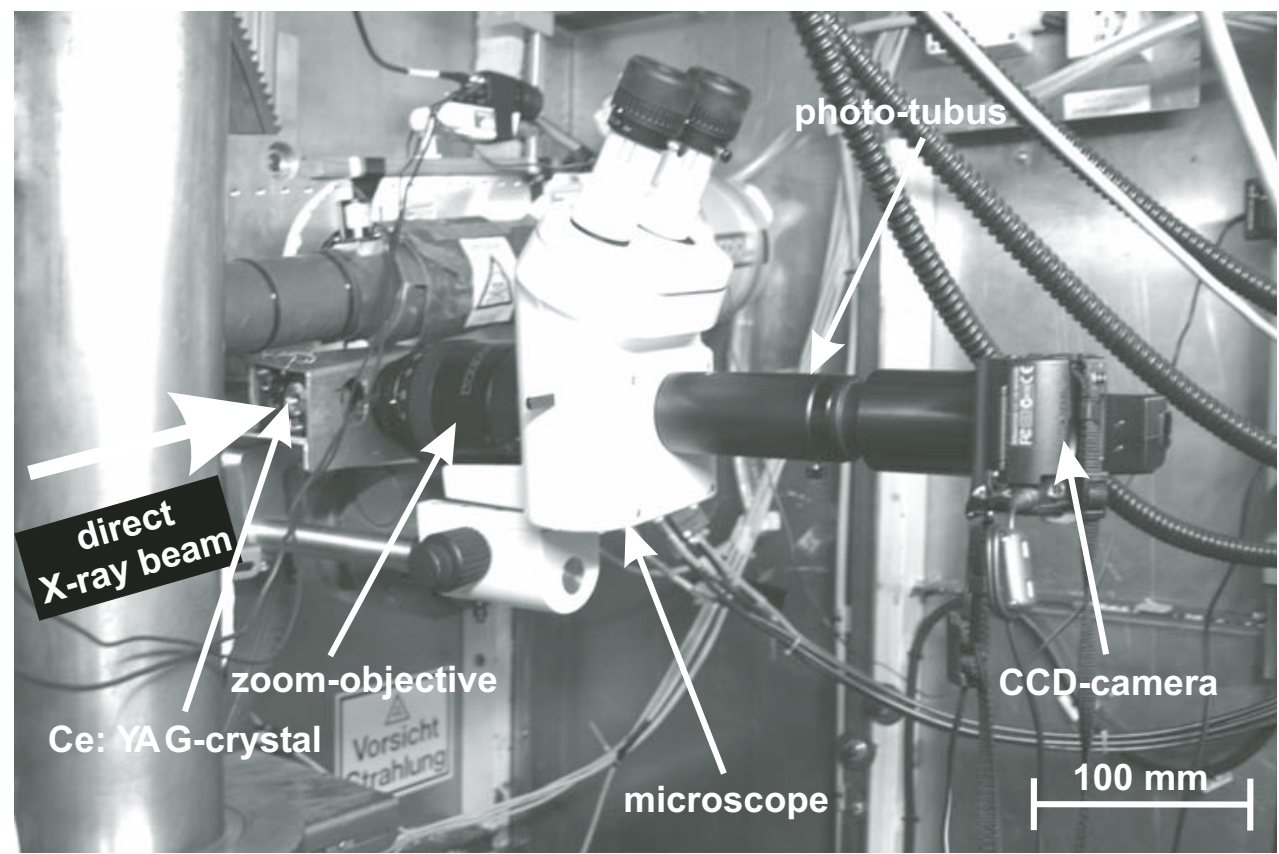

Figure 4. MAX80 showing X-radiography equipment assembled below the Ge-solid-state detector for energydispersive X-ray diffraction. The lead shielding limits the scattered radiation. The objective of the microscope is required to magnify the shadow graph of the sample to the chip size of the CCD (Charge-Coupled Device) camera to get an optimum resolution of the saved image.

selection of useful objectives. We assembled the objective of a microscope and a 5 megapixels color CCD camera able to take images and videos as well (Fig. 4).

The evaluation of the shadow graphs in terms of sample length measurement is performed by densitometry profiling, i.e., image processing software analyzes the brightness of the image along a predefined line. Therefore the image is transformed into a black and white gray-scale image. Because most of the minerals under investigation do not have a distinct difference in X-ray absorption with respect to the other parts of the setup, $5-\mu \mathrm{m}$-thick gold foils are used as markers. Figure 5 shows the shadow graph of a clinoenstatite specimen in between an $\mathrm{Al}_{2} \mathrm{O}_{3}$ part (top) and the $\mathrm{NaCl}$ pressure standard (bottom) and the corresponding image-processing evaluation. The dark shadow inside the $\mathrm{NaCl}$ standard close to the clinoenstatite interface corresponds to the thermocouple.

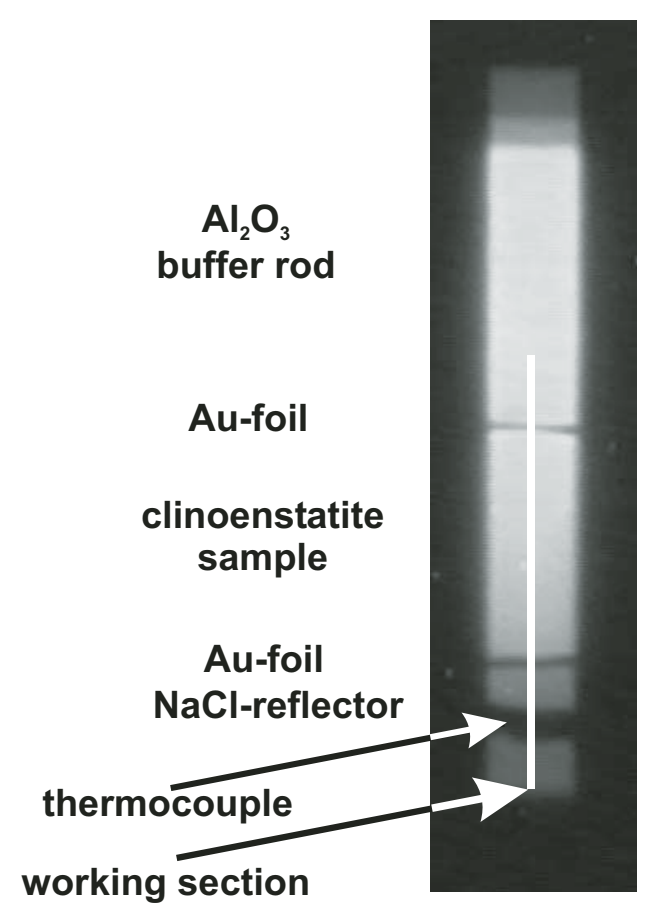

Figure 5. Sample length measurement under in situ conditions by image processing of X-ray shadow graphs. The X-ray shadow graph (left) shows a clinoenstatite sample between an $\mathrm{Al}_{2} \mathrm{O}_{3}$ buffer rod (top) and the $\mathrm{NaCl}$ reflector (bottom). The black part inside the reflector is the thermocouple. The density difference between the three parts is too small for a secure sample length determination. Gold foils serving as ultrasonic bonds at the same time are placed between the adjacent parts as markers. The white line inside the shadow graph is the gauge length evaluated by the image-processing system. The resulting sample length measured in pixels is transformed to millimeters by the initial calibration image of the sample with a given length. Because the pixel size corresponds to $0.0044 \mathrm{~mm}$, the sample shown in the shadow graph has a length of $0.635 \mathrm{~mm}$. 


\section{Ultrasonic Interferometry}

Frequency sweep. Corresponding to the crucial importance seismology has for the exploration of Earth's deep interior, elastic-wave velocity measurements under simulated mantle conditions allow us to "better" interpret seismic observations. Because the sample size has to be larger than the ultrasonic wavelength, high-pressure measurements have to be performed in the ultrasonic frequency range- - lower $\mathrm{MHz}$ range for multianvils, upper $\mathrm{MHz}$ to $\mathrm{GHz}$ range for diamond anvil cells (DAC). The classical traveltime method, common in rock physics, is not useful because the ultrasonic transducers are too brittle and too temperature sensitive to put them inside the high-pressure cell. Assembling them outside this cell, e.g., at the rear side of the anvils (see Fig. 6), results in a very long entire travel path in comparison to the sample length. For the configuration shown in Figure 6 , the sample length is only $5 \%$ of the whole travel path. The

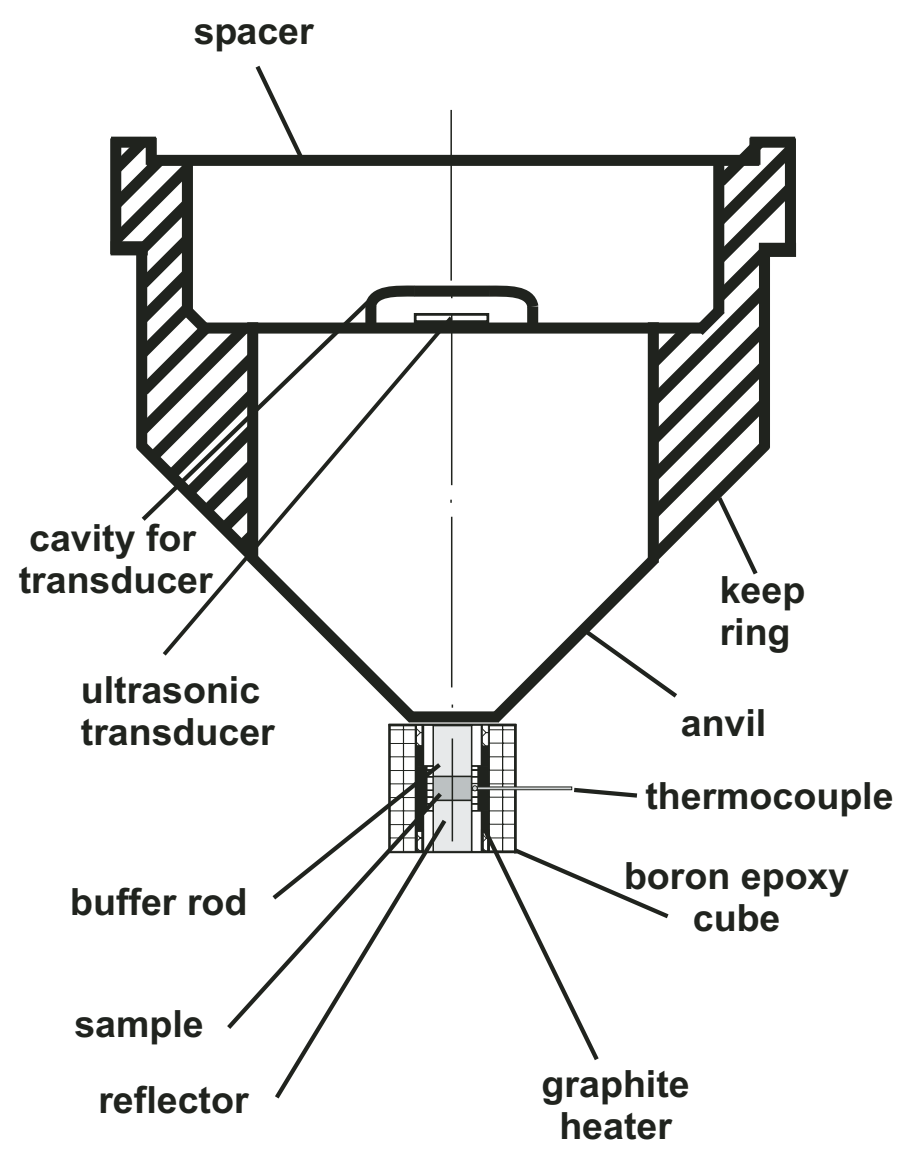

Figure 6. MAX80 sketch of ultrasonic top anvil and high-pressure cell assembly. For ultrasonic interferometry, the spacer needs a cavity to keep the brittle ultrasonic transducer free of any mechanical stress. The generated ultrasonic waves travel along the anvil axis, enter the buffer rod and the sample, and are finally reflected at the sample-reflector interface. Ultrasonic interferometry evaluates the superposition of the waves reflected from the buffer-sample and sample-reflector interface. The $\mathrm{NaCl}$ reflector is also used as pressure standard measured by $\mathrm{X}$-ray diffraction. resulting accuracy would be insufficient. Contrary to the direct traveltime measurement, ultrasonic interferometry uses the interference between the incident and reflected waves inside the sample. This way, the technique becomes relatively independent of the length of the travel path but requires a careful optimization of the reflection coefficients at all interfaces. Otherwise, the level of the ultrasonic energy reflected after passing the sample becomes too low for evaluation. To evaluate the reflected signals, the parts representing the reflection from the sample's front and rear face are selected and digitally interfered. The result is a periodically and equidistantly changing energy level (constructive and destructive interference) as a function of frequency. The periodicity of the interference pattern results in a much higher precision $(0.2 \%-1.5 \%), 1-3$ times higher (Schreiber et al., 1973; Li et al., 1998) than classical traveltime methods (Birch, 1960, 1961).

The technique was first described by McSkimin (1950). Kinoshita et al. (1979) and Fujisava and Ito $(1984,1985)$ took the first steps to adapt the method to cubic anvil apparatus and uniaxial split-sphere apparatus. In the 90th, Li et al. (1994, 1995a, 1995b, 1996a, 1996b, 1996c) optimized the method for multianvil devices and pushed pressures and temperatures to transitionzone conditions.

To adapt MAX80 to ultrasonic interferometry, the spacer located between upper and lower anvil and corresponding bolster had to be replaced by a redesigned part that had a cavity at one side to keep the ultrasonic transducers free of any stress (Fig. 6). In principle, two types of ultrasonic setups were used in MAX80 - symmetrical and asymmetrical ones. Symmetrical setup means that the buffer and reflector (the parts above and below the sample, see Fig. 6) are made from the same material and have the same shape. Consequently, the measurements can be performed from both sides of the sample. Asymmetrical setups permit optimization of the reflection coefficients in the cell assembly to a great extent, but they require the transducers for generation and detection of elastic compressional (P) and shear (S) waves to be attached to the same anvil. Using single-mode transducers for generating pure $\mathrm{P}$ or S waves, respectively, four transducers in a relatively large cavity have to be cemented to the anvil slightly eccentric. For symmetrical setups, one single transducer ( $\mathrm{P}$ or $\mathrm{S}$ ) is cemented at the top and bottom anvil. Because the transducers act sequentially as generator and receiver of ultrasonic waves, a directional bridge is needed to prevent the strong excitation wavelet from hitting the sensitive input of the receiving amplifiers. The transducers are overtone-polished $\mathrm{LiNbO}$ disks with a natural frequency of $33.3 \mathrm{MHz}$. The usual sweep range is $5-65 \mathrm{MHz}$ with a frequency step of $100 \mathrm{kHz}$, i.e., a sinusoidal wavelet of frequency $x$ is transmitted to the transducer, the reflected signal is received, digitized, and saved in a computer, next the wavelet with the frequency $x+100 \mathrm{kHz}$ is transmitted to the transducer, and so on (Mueller et al., 2003, 2005a).

Data transfer function technique. The major problem of all classical ultrasonic interferometry is that it is very timeconsuming, e.g., a $60 \mathrm{MHz}$ frequency sweep with $100 \mathrm{kHz}$ steps lasts for more than $30 \mathrm{~min}$. Acquisition of the raw data for both 
velocities $\left(V_{\mathrm{p}}\right.$ and $\left.V_{\mathrm{s}}\right)$ requires $\sim 1 \mathrm{~h}$. This is much slower than the parallel-performed XRD, X-radiography, temperature measurement. Transient measurements are impossible. One solution for this time problem with the sweep technique is to perform all the single measurements of the sweep technique at the same time. This has become available only recently. It is the data transfer function (DTF) technique. The first mineral physics use of this technique was published by $\mathrm{Li}$ et al. (2002). Independent from that, a similar method was developed for MAX80 at HASYLAB (Mueller et al., 2005a). For that purpose, an excitation function is calculated stimulating all the frequencies inside the whole needed frequency range. This is the Fourier transform of the frequency range in time domain. To further improve the DTF technique, the transient response of the ultrasonic transducer, its resonance curve, and the parameters of the arbitrary waveform

reproduced from DTF: 2 Mio data points

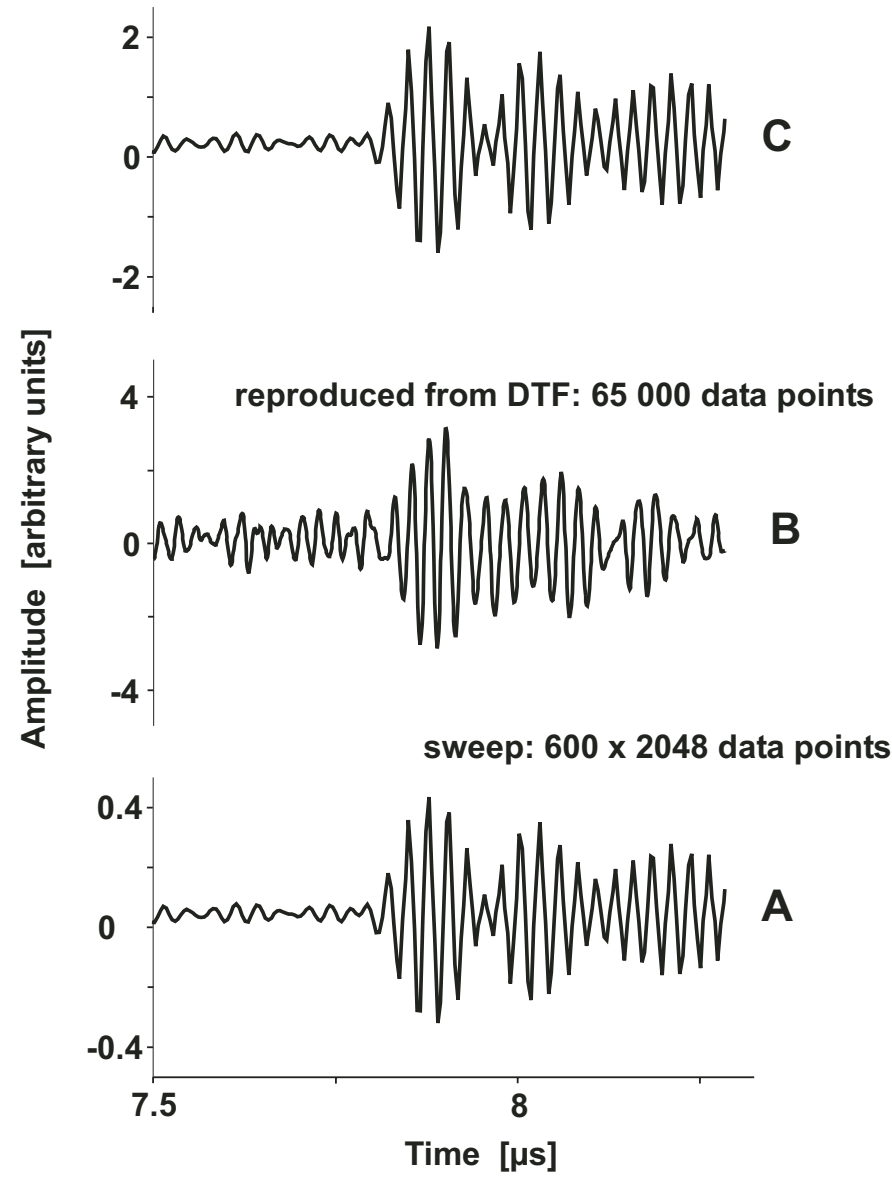

Figure 7. Reproduction of monochromatic ultrasonic signals from the data transfer function (DTF) by convolution in dependence on DTF resolution. The DTF technique requires a very high resolution of the saved DTF, because the DTF represents the superposition of an infinite quantity of monochromatic responses between the upper and lower cutoff frequencies. Otherwise, the reproduced single-frequency response does not correspond to the signal saved at monochromatic excitation. generator, which transforms the calculated function to an electrical signal, are taken into account. This is a modified "raised cosine function" produced by a digital filter. The response of the working section to this excitation is the data transfer function (DTF), which includes, in analogy to the excitation function, the responses of all monochromatic waves between the upper and lower cutoff frequencies. Saving the received DTF completes the measurement. This process lasts 2-30 s depending on resolution and equipment. Using triple-mode transducers (see a following section on ultrasonic interferometry), the saved DTF contains the same information content as the results of a 1-h-long measurement with the sweep technique. To reproduce the response for each single frequency, the data transfer function is convolved with the single frequencies. The convolution theorem states that the convolution of two functions corresponds to the multiplication of its Fourier transforms.

The expenditure of time is shifted from the experiment to the adjacent mathematical evaluation. The further evaluation corresponds to that of the sweep technique. The DTF technique requires an extremely high resolution of the saved DTF. This function (DTF) is the superposition of an infinite quantity of monochromatic responses between the upper and lower cutoff frequencies. Consequently, the resolution has to be high enough so that even the monochromatic frequency with the lowest amplitude can be resolved after the convolution of the DTF. Otherwise, the reproduced monochromatic response is distorted. Because the Fourier transform is performed numerically by fast discrete Fourier transform (FFT), the signal has to be saved with three times the duration of the evaluation range, at a minimum, to prevent its distortion by breakoff effects. For a bandwidth of $60 \mathrm{MHz}$ and a travel time of $\sim 15 \mu \mathrm{s}$, the DTF should be saved with a duration of $50 \mu$ s and a resolution of 200,000 data points at a minimum (Fig. 7). Only the DTF technique makes ultrasonic interferometry adequate for synchrotron facilities without restrictions and suitable for transient measurements (Li et al., 2002; Mueller et al., 2005a).

\section{Double-Stage DIA-Type Multianvil MAX200x}

\section{Pressure Generation}

MAX200x was planned as a supplement to and continuation of the development of MAX80 in order to be able to simulate Earth's transition-zone conditions with similar or even bigger-sized samples. All experiences gathered at visits to the multianvil apparatus at NSLS (National Synchrotron Light Source), APS (Advanced Photon Source) and SPring-8 in 2002 and 2003 were taken under consideration. In order to minimize the deviatoric stress inside the second-stage anvil cubes, MAX200x was also designed as a DIA-system. A maximum load of 1750 tons will guarantee pressures of $25 \mathrm{GPa}$ in a large sample volume. All techniques described for MAX80-XRD, $\mathrm{X}$-radiography, and ultrasonic interferometry are available with MAX200x. The hydraulic ram was designed and manufactured by Max Voggenreiter GmbH (mavo) as a classical four-column 


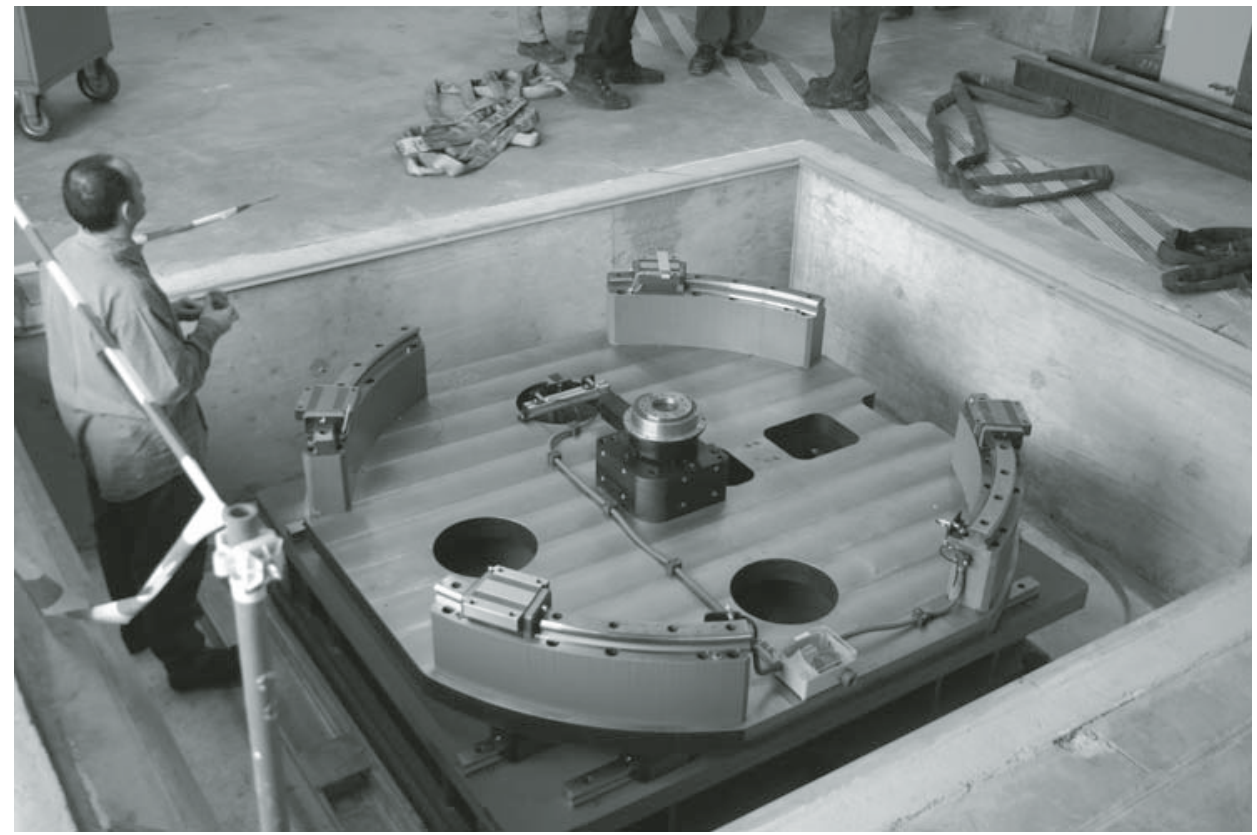

Figure 8. MAX200x rotation table assembled in the pit at HARWI-II hall at Deutsches ElektronenSYnchrotron (DESY) - HAmburger SYnchrotron LABor (HASYLAB). Adjusting MAX200x to the synchrotron beam requires three different machine tables: rotation, lateral displacement, and lifting. Because the synchrotron beam has a position of only $1200 \mathrm{~mm}$ above the ground of the experiment hall, a pit of $3700 \mathrm{~mm}$ length, $3220 \mathrm{~mm}$ width, and $1400 \mathrm{~mm}$ depth had to be constructed.

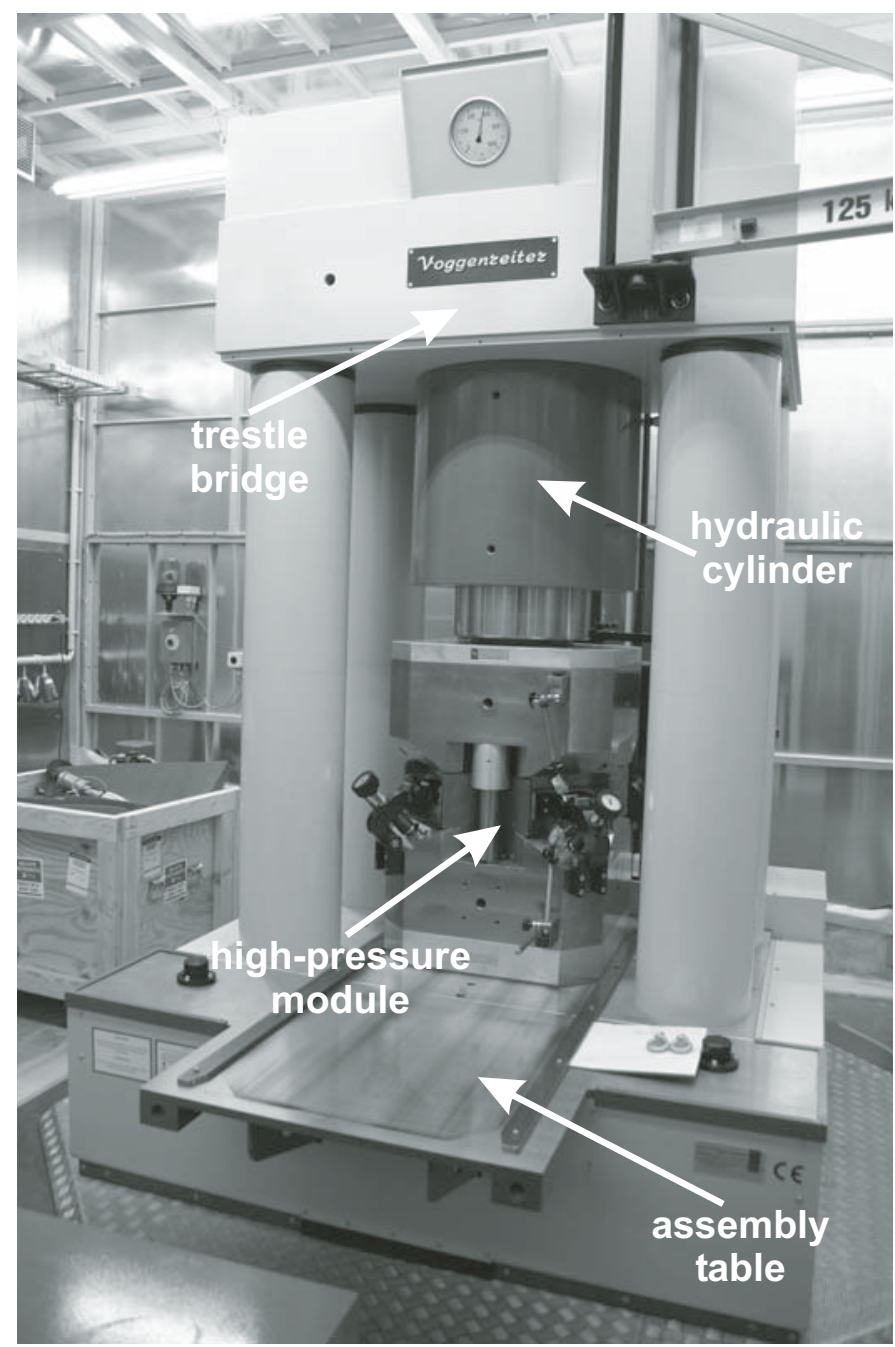

press frame with oil-pressure storage device, i.e., the oil pressure can be held without continuous pumping. The maximum load is reached by applying an oil pressure of 700 bars in the working cylinder suspended from the trestle bridge. To be able to align the specimen to the fixed synchrotron beam, the whole press can be positioned by a combination of three machine tables for rotation, horizontal shift, and lifting with a precision of $0.01 \mathrm{~mm}$ and $0.01^{\circ}$, respectively. As the synchrotron beam has a position of only $1200 \mathrm{~mm}$ above the ground of the experiment hall, a pit of $1400 \mathrm{~mm}$ depth with a 500 -mm-thick concrete foundation had to be constructed to support the total weight of $\sim 30$ tons. Figure 8 shows the assemblage of the bottom rotation table in the pit.

As described in the previous section on pressure generation, MAX200x also needs two load frames to drive the four lateral anvils. The design of the module, in principle an enlarged version of MAX80's parts, had to be adapted to bigger size and weight. The bottom load frame together with the lateral reaction bolsters can be mechanically pushed to the front of the press using a motor-driven thrust chain for the replacement of the highpressure cell. Figure 9 shows MAX200x inside the hutch with the module in working position. The second stage consists of eight 32-mm-long tungsten carbide anvils, each with a truncation directed to the center of the arrangement that will compress an octahedron equipped with specimen, pressure standard, internal

Figure 9. MAX200x assembled at HARWI-II hall inside the hutch with module in working position. For high-pressure cell replacement, the whole module can be mechanically pushed to the assembly table at the front side of the press. 

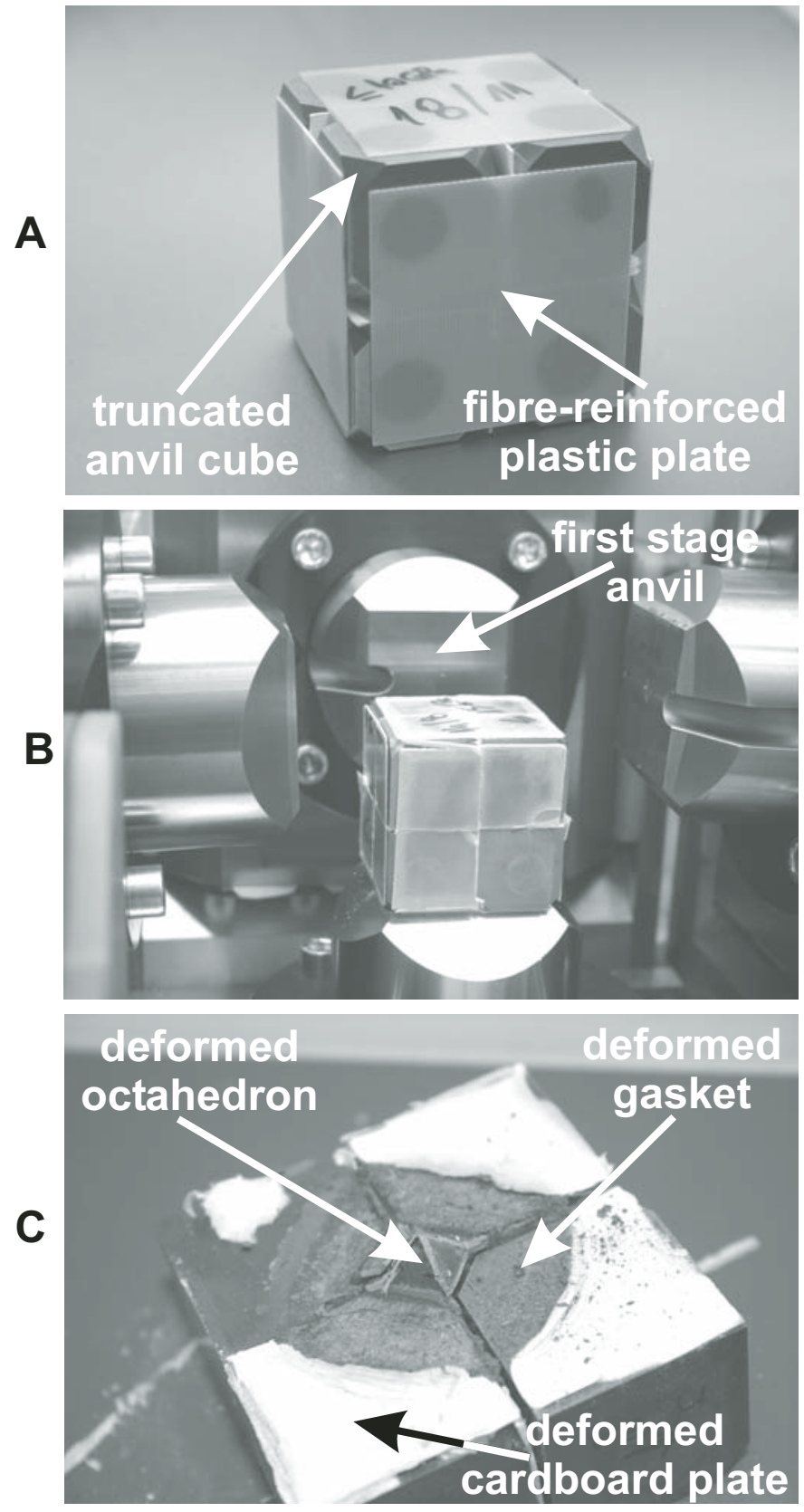

Figure 10. MAX200x second-stage setup: (A) ready for use, where six fiber-reinforced plastic plates keep the second-stage anvils together; (B) after the high-pressure experiment, where the plastic plates are broken because of the compression of the setup; and (C) high-pressure setup dismounted in part after the run, where the upper four anvils have been removed. The deformed octahedron with strongly deformed gaskets is visible. The white cardboard plates support the gaskets and limit their deformation.

electrical heater, and further parts if necessary. The octahedron is surrounded by prefabricated gaskets made from pyrophyllite. The setup is held together by glue on plates of fiber-reinforced plastic. Figures 10A-10C show a second-stage setup before and after a high-pressure experiment with the maximum load of 1750
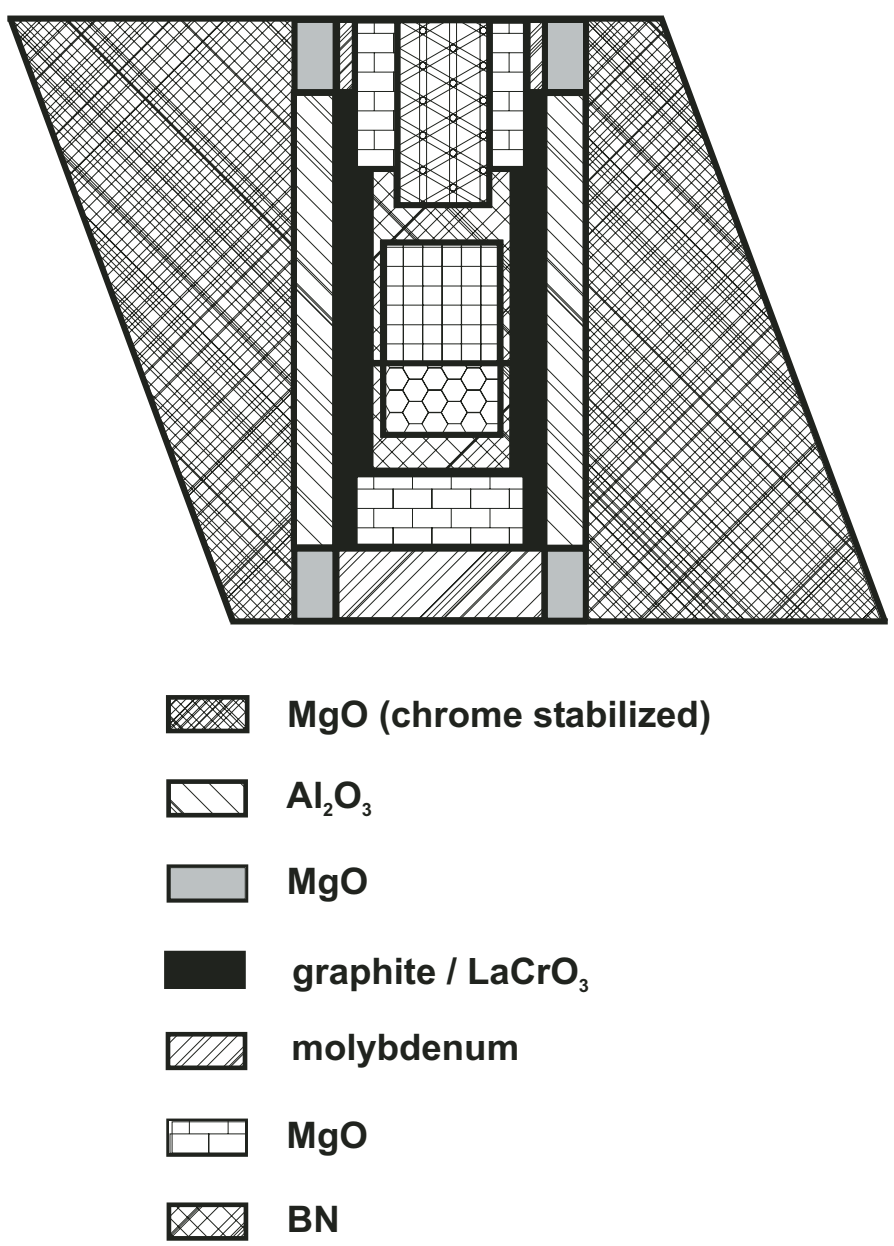

\section{Au / BN standard}

\section{sample}

$D$ four-hole alumina sleeve

Figure 11. MAX200x showing internal (10/5) octahedron-cell assembly for X-ray diffraction (XRD). The $\mathrm{Al}_{2} \mathrm{O}_{3}$ sleeve is used for thermoinsulation. The molybdenum parts lead the heating current to the stepped graphite heater. Stepping the heater results in a decreased temperature gradient along the sample axis, because the stronger heat production at the ends compensates for the heat losses to the anvils in part. An alumina sleeve with four holes carries the thermocouple. The $\mathrm{Au} / \mathrm{BN}$ standard is used as X-ray diffraction pressure marker.

tons, as well as the setup dismounted in part after the run. The setup inside the octahedron (Fig. 11) is derived and adapted from that of MAX80 (Huppertz, 2003; Leinenweber, 2005; Mueller et al., 2005a, 2005b).

The pressure calibration was performed for different highpressure cell assemblies: $11 / 8,10 / 5$, and $7 / 3$. The octahedra were made from sintered $\mathrm{MgCr}_{2} \mathrm{O}_{4}$ using $95 \%$ high-purity $\mathrm{MgO}$. The pressure was measured by energy-dispersive X-ray 
diffraction using the high-pressure equation of state for $\mathrm{MgO}$ (Jamieson et al., 1982). Figure 12 shows the results for the first series of experiments.

\section{Synchrotron Radiation Facilities and Measurements}

The three centers of the Helmholtz-Gemeinschaft DESY, GKSS (Gesellschaft für Kernenergieverwertung in Schiffbau und Schiffahrt mbH), and GFZ (GeoForschungsZentrum Potsdam) jointly operate the new high-energy beam-line HARWI-II at the storage ring DORIS III at HASYLAB. To penetrate deeply into materials, the optics of the beam line were designed to provide a white beam of $0.5 \mathrm{~mm}$ diameter and a $50 \mathrm{~mm} \times 10 \mathrm{~mm}$ monochromatic X-ray beam with an energy range of 20-250 keV.

The design goal for the new HARWI-wiggler was a maximized flux at $100 \mathrm{keV}$ at an aperture of $\sim 1 \mathrm{~cm}$. The new device delivers a factor of 20 more energy than the old wiggler at the HARWI-beam line. Figure 13 shows the flux graphs calculated for $1 \times 1 \mathrm{~mm}$. In a wide range, the flux scales linearly with the area of aperture. The total power is $28 \mathrm{~kW}$, and the on-axis power density reaches $41 \mathrm{~kW} / \mathrm{mrad}$. Right after the exit chamber of the wiggler-beam a horizontal slit is positioned that defines the height of the beam. A $1.5 \mathrm{~mm} \mathrm{C}$-filter is permanently installed as a high pass filter to limit the heat generation by X-ray absorption in the cell assemblies. An additional $\mathrm{Cu}$-filter is available for experiments using high-energy radiation (above $60 \mathrm{keV}$ ). The Be-window at the front end has a distance of $\sim 38 \mathrm{~m}$ from the center of the wiggler. The white beam for MAX200x has a diameter of $0.7 \mathrm{~mm}$ (Fig. 14). Two types of monochromators are operated in vacuum. A double Laue monochromator in horizontal geometry delivers beams of $10 \times 10 \mathrm{~mm}$ in size with an energy range

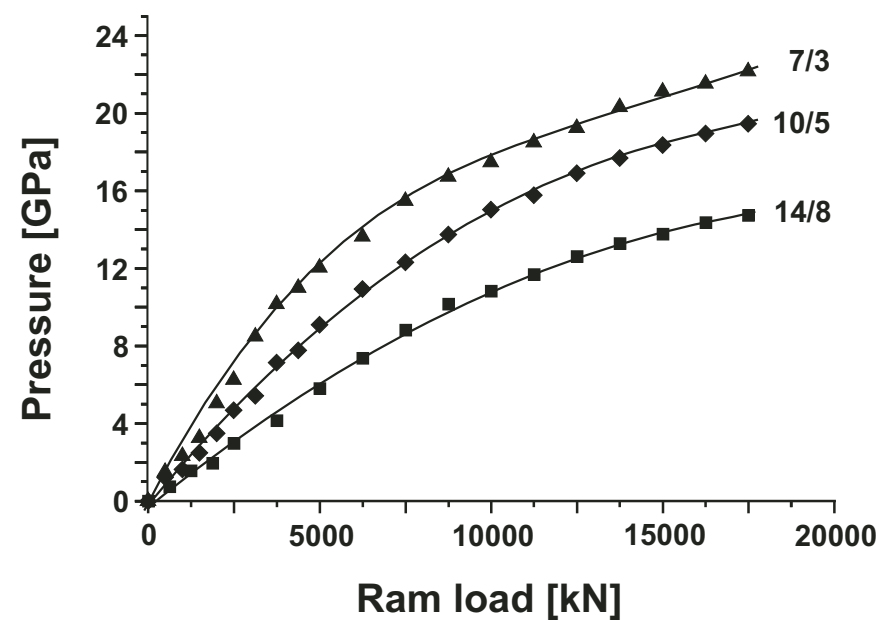

Figure 12. MAX200x pressure calibration for $14 / 8,10 / 5$, and $7 / 3$ cell assemblies using X-ray diffraction (XRD) and the equation of state for $\mathrm{MgO}$ (Jamieson et al., 1982). The octahedra were made from sintered $\mathrm{MgCr}_{2} \mathrm{O}_{4}$ using $95 \%$ high-purity $\mathrm{MgO}$. The first number of the cell specification marks the edge length of the octahedron; the second number (after the slash) marks the truncation edge length of the second-stage anvils. of 50-250 keV and an offset of $3 \mathrm{~cm}$ of the diffracted beam. The required monochromator tank is $3 \mathrm{~m}$ long, $2 \mathrm{~m}$ broad, and $1 \mathrm{~m}$ high. It is designed and operated by GKSS. The second monochromator produces a beam of $50 \mathrm{~mm}$ in width and $10 \mathrm{~mm}$ in height in a vertical diffraction geometry optimized for imaging techniques like tomography and Diffraction-Enhanced Imaging (DEI) performed by the partner institution GKSS at the joint beam line. The energy ranges from $\sim 20 \mathrm{keV}$ up to $200 \mathrm{keV}$. The beam offset is $\sim 4 \mathrm{~cm}$ (Beckmann et al., 2003).

The primary slit is a SL-V-TU-200-10 from Advanced Design Consulting Inc. (ADC), a high-precision slits system with four tungsten blades driven by a stepper motor with a maximum aperture of $25.4 \mathrm{~mm}$. Because the distance between the beam parts (see Fig. 14) exceeds the slits' aperture, the slits system is tied to the vacuum tube by metal bellows and can be shifted. The high-energy white beam is sent through a vacuum cube as long as possible to limit the energy loss of the incident beam by scattering to air molecules and to decrease the resulting scattered radiation inside the hutch at the same time.

The horizontal goniometer (mavo) is mounted on the optical Table 117-0000-4 (ADC) equipped with eleven stepper motors.

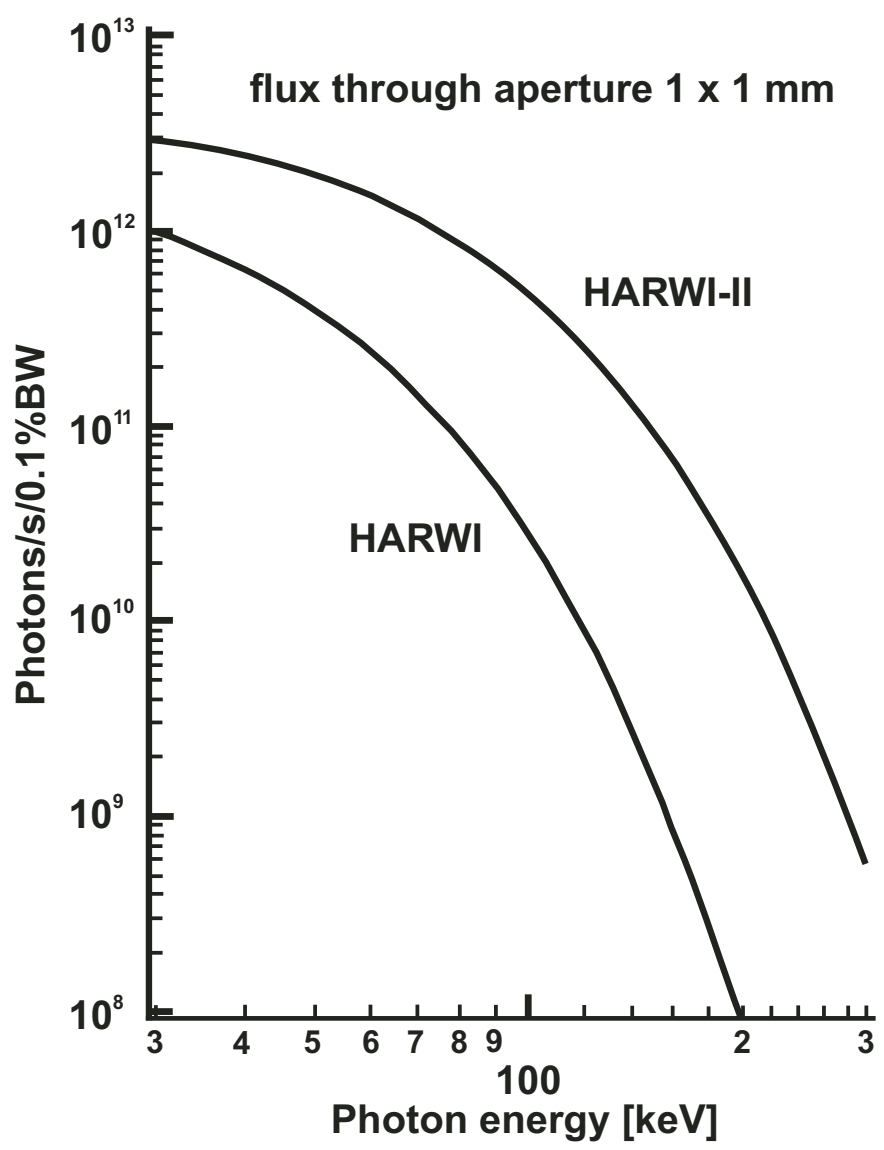

Figure 13. MAX200x flux comparison through a small aperture of $1 \times 1 \mathrm{~mm}$ for the old (HARWI) and the new designed HARWI-II-wiggler. Over a broad photon energy range, the new wiggler produces a one order of magnitude higher flux (modified from Beckmann et al., 2003). 


\section{HARWI-II - beams}

\section{output of monochromator}

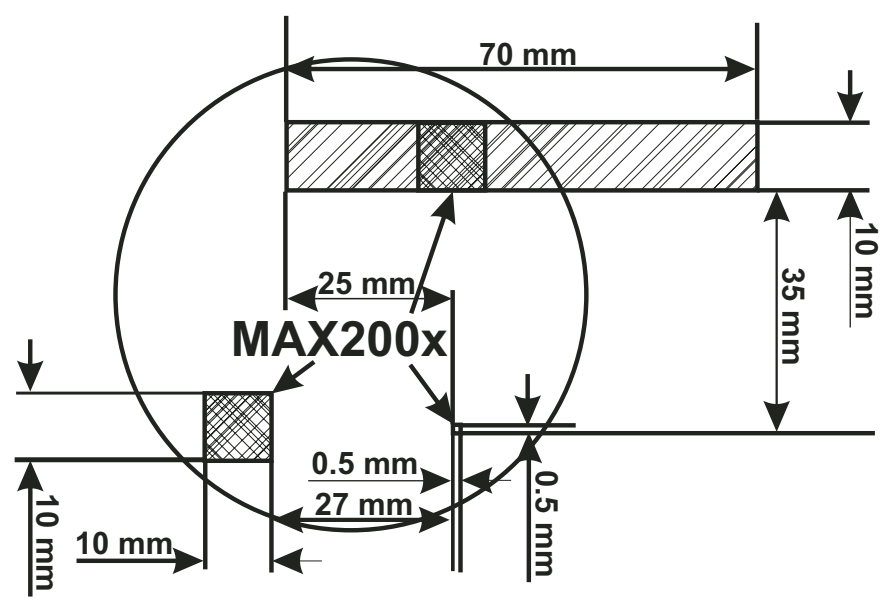

Figure 14. MAX200x X-ray beam size, shape, and location at the exit of the optics hutch of the HARWI-II beam line. The small white beam is used for energy-dispersive X-ray diffraction (XRD). Contrary to MAX80, X-radiography has to be performed using monochromatic beams because of the higher flux and higher energy range. In addition, monochromatic radiation results in higher resolution of the saved shadow graphs (modified from Beckmann et al., 2003).
The Ge-coaxial-detector GLP-06165/05P by ORTEK (resolution at $5.9 \mathrm{keV}=170 \mathrm{eV}$; resolution at $122 \mathrm{keV}=504 \mathrm{eV}$ ) is tipped with two high-precision slits SL-A-TU-100-10 (ADC) at a distance of $\sim 1500 \mathrm{~mm}$ from each other to block scattered radiation and diffracted X-rays from nonsampled parts of the high-pressure cell.

For converting the X-ray shadow graphs and decoupling the optical images, the same design as that for MAX80 was adopted. The optical system consists of the macroscope Z16 APO A and the 1.4 megapixels black-and-white CCD camera DFC 350FX (Fig. 15). Transmitted using a Fire-Wire controller and four repeaters because of the long cables, the images are saved to a computer hard drive outside the hutch. The optimum macroscope-camera combination was selected by an experiment using a double-blind study from 13 options.

Two ionization chambers, IONIKA DN160 ISO-K, are available to measure X-ray absorption.

\section{Ultrasonic Interferometry}

Triple-mode transducers. The way to perform ultrasonic measurements with a double-stage multianvil apparatus such as MAX200x is to attach a transducer to the anvil cubes of the second stage. The only option to do this is the small triangular truncation at the outer side of the whole setup opposite to the same truncation that compresses the octahedron. With a 10/5 setup, the available space is a triangle with an edge length of $5 \mathrm{~mm}$ suitable for cementing a transducer disk of $3.8 \mathrm{~mm}$ in diameter.

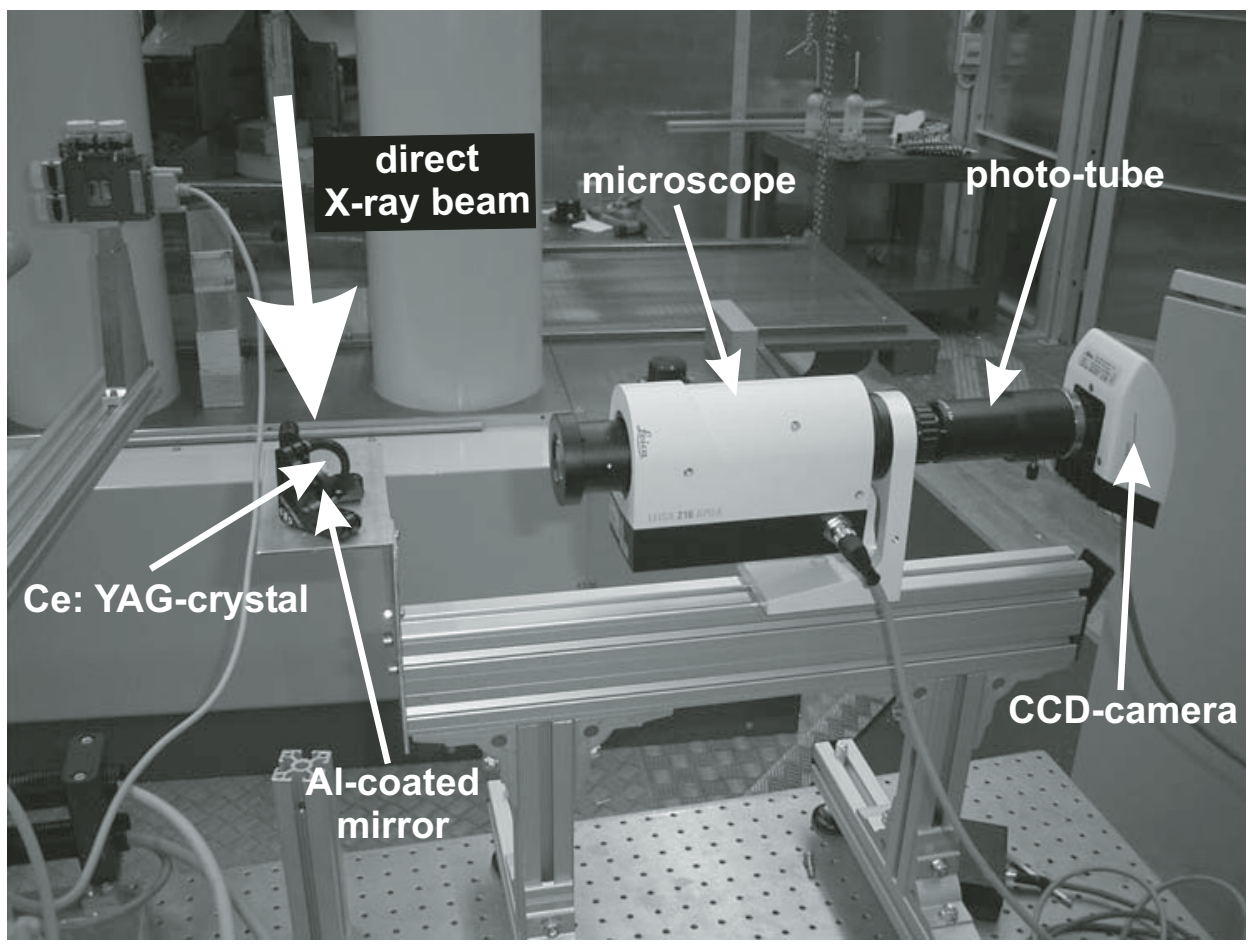

Figure 15. MAX200x X-radiography equipment. A Ce:YAG (Cerium doped Yttrium Aluminum Garnet) crystal ([by courtesy of IKZ (Institut für Kristallzüchtung)]) converts the X-ray shadow graph to an optical image. An Al-coated mirror decouples the optical from the nonconverted X-ray image. The optical system consists of the microscope Z16 APO A and the 1.4 megapixel blackand-white CCD (Charge-Coupled Device) camera DFC 350FX. 

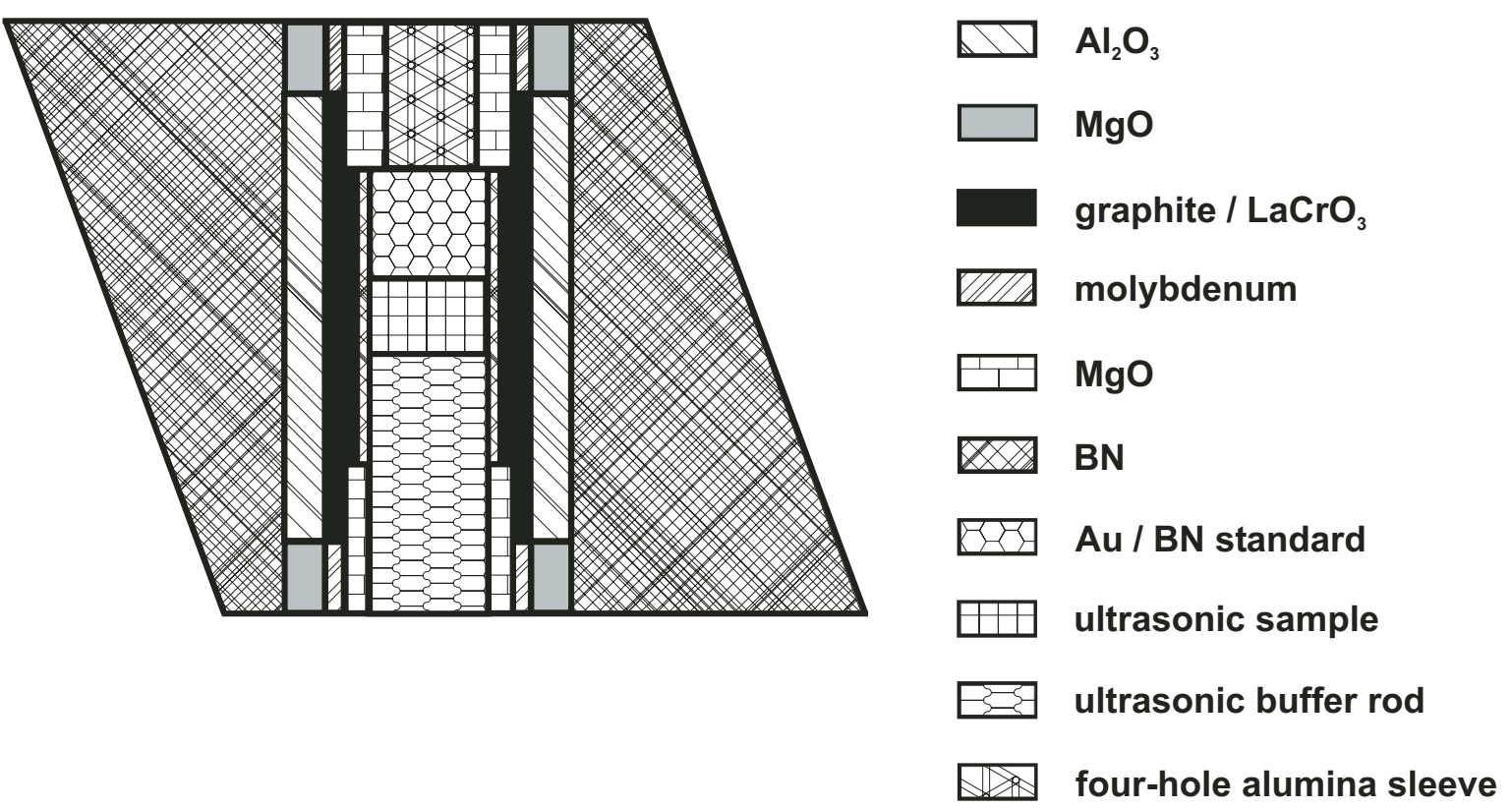

Figure 16. MAX200x internal (10/5) octahedron-cell (asymmetrical) for ultrasonic interferometry in conjunction with X-ray diffraction. Ultrasonic interferometry requires the exchange of some parts. The hot-isostatic pressed sample is located between the reflector used as pressure standard at the same time (top) and the buffer rod (bottom).

Another option is to use anvil cubes made with one additional greater truncation for ultrasonic experiments. If an asymmetrical ultrasonic configuration (Fig. 16) (see also the previous section on Ultrasonic Interferometry) is used, triple-mode transducers made from $\mathrm{LiNbO}$ are needed to generate compressional, shear, and dual-mode waves at the same time (Fig. 17), because there is no further space available to attach more than one transducer (Li et al., 2004; Li et al., 2005). At the same time, this method also accelerates transient measurements because all the needed information to measure the velocities of $\mathrm{P}$ and $\mathrm{S}$ waves is saved within one single file. Figure 18 shows the electronic equipment for DTF ultrasonic interferometry for MAX200x.

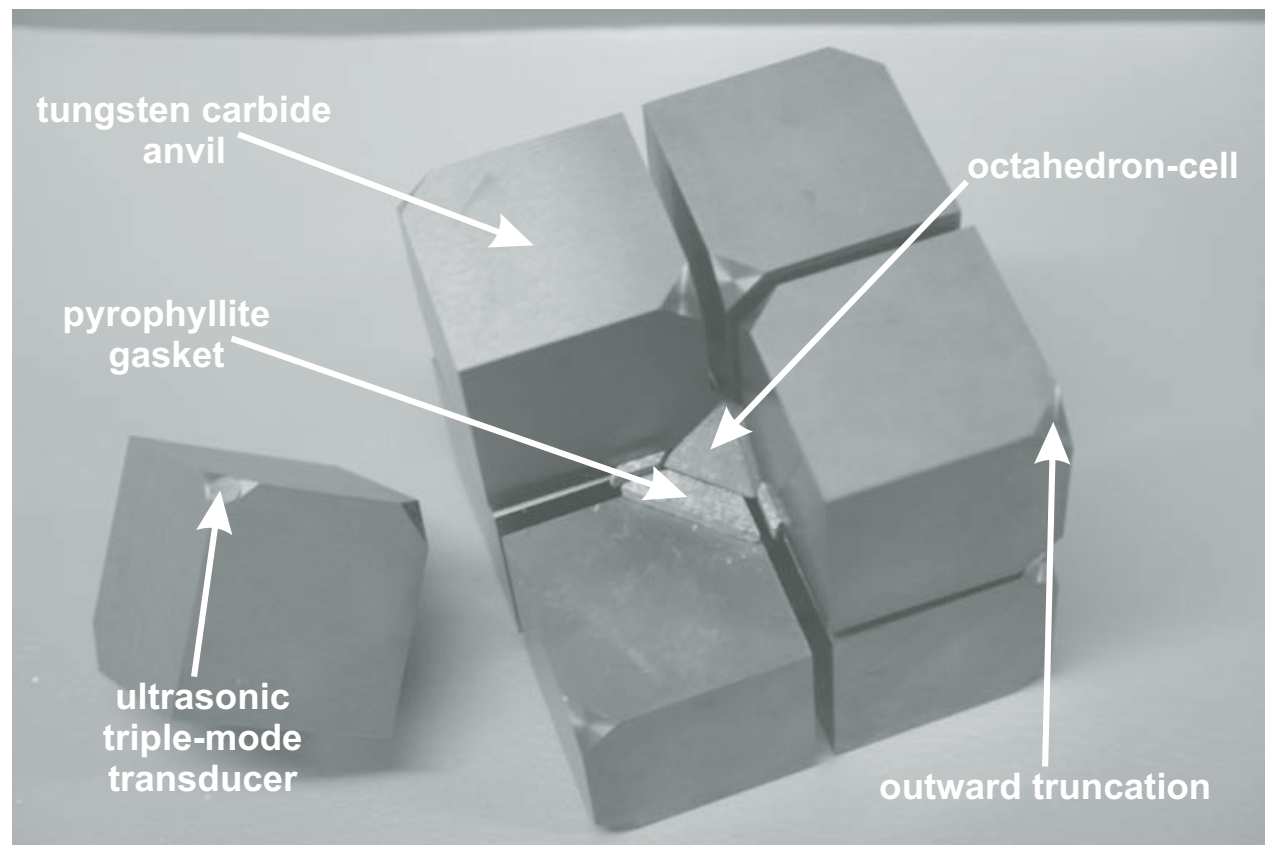

Figure 17. MAX200x second-stage cell with ultrasonic transducer cemented on one outward anvil truncation. For demonstration, the gaskets are not glued on the anvils. The cardboard plates, the self-adhesive Teflon tape, and the glassfiber reinforced epoxy sheets are also removed. Use of a triple-mode transducer (10/ rotated Y-cut $\mathrm{LiNbO}_{3}$ ) allows the elastic-wave velocity measurement of compressional and shear waves to be performed at the same time. 


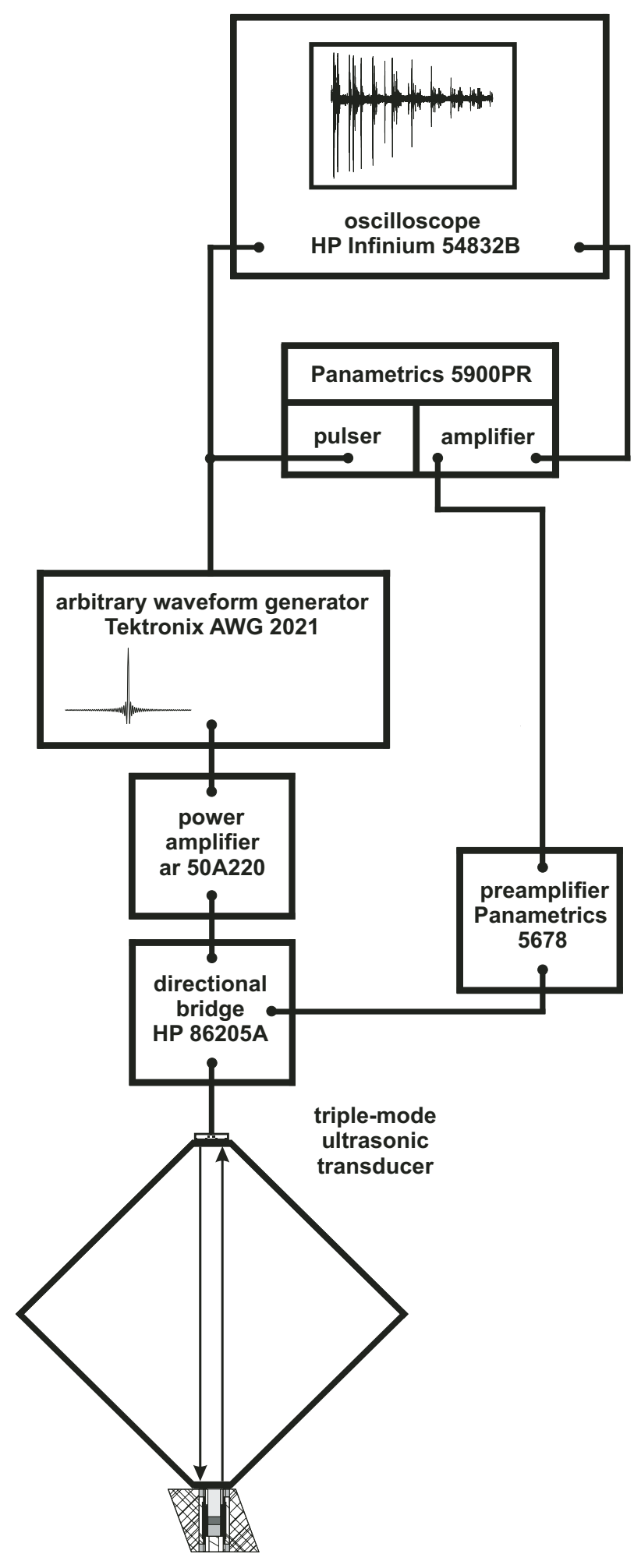

Figure 18. MAX200x electronic equipment for data transfer function (DTF) ultrasonic interferometry. The arbitrary waveform generator transforms the calculated excitation function into an electric signal, which is applied to the transducer via a power amplifier. The directional bridge prevents the sensitive pre-amplifier from being destroyed by these strong signals.

\section{RESULTS AND DISCUSSION}

\section{Multistaging Experiments: NaCl}

A promising way to increase the maximum pressure of multianvil devices is "multistaging," i.e., implementing an additional set of "subanvils" between the anvils and sample, which results in a better distribution and limitation of the stress inside the anvils. Contrary to the common opinion of overshooting the maximum crushing strength, most of the anvils fail in high-pressure experiments because the maximum tensile stress is exceeded as a result of lateral deformation. Utsumi et al. (1986) published a technique to reach $60 \mathrm{GPa}$ pressure by using sintered diamond anvils as second stage in a single-stage DIA-type multianvil apparatus. Wang and Utsumi (2005, personal commun.) reported similar experiments performed in a deformation-DIA (D-DIA). There was a strong indication that more than $70 \mathrm{GPa}$ can be reached by additional uniaxial stress starting from $65 \mathrm{GPa}$ under hydrostatic conditions.

As our first approach, we performed similar experiments using fine-grained tungsten carbide as anvil material inside an $8 \mathrm{~mm}$ boron epoxy cube. The anvils had a conical shape with a cylindrical shaft. The specimen, a 1:1 mixture by volume of $\mathrm{NaCl}$ and $\mathrm{BN}$ placed between both front faces, was enclosed

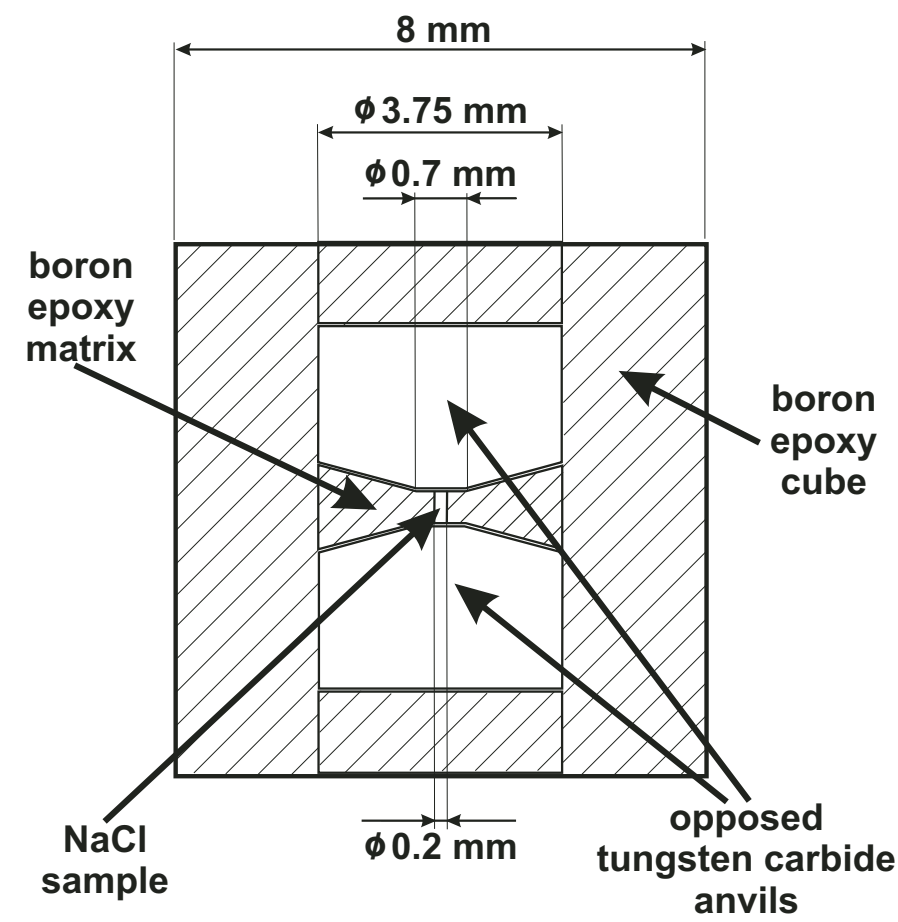

Figure 19. MAX80 opposed-anvil-type setup inside a single-stage multianvil $8 \mathrm{~mm}$ boron epoxy cube (based on Utsumi et al., 1986). The advance of MAX80's top and bottom anvils compresses the sample between the opposed anvils. The advance of the four lateral anvils prevents the boron epoxy matrix from being squeezed out. 


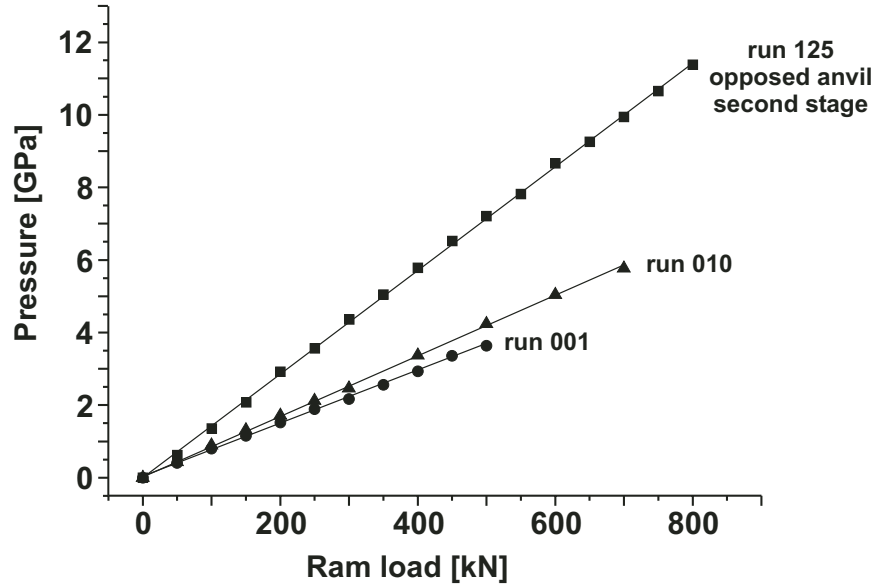

Figure 20. MAX80 pressure-doubling by additional opposed-anvil configuration (run 125) in comparison to two single-stage runs using the same anvil truncation of $6 \mathrm{~mm}$. The pressure inside the $\mathrm{NaCl}$ sample was measured by X-ray diffraction (XRD) using the equation of state by Decker (1971).

in a boron epoxy matrix with an internal diameter of $0.2 \mathrm{~mm}$ (Fig. 19). The experimental results showed a pressure doubling in comparison to the original $8 \mathrm{~mm}$ cell assembly. Figure 20 compares the pressure data for the double-stage experiment measured by XRD using the Decker scale (Decker, 1971) with the results for an original $8 \mathrm{~mm}$ cell. The lower maximum pres- sure in comparison to Utsumi et al. (1986) is due to the porosity of the manually compressed specimen and the nonoptimum conical surface of the boron epoxy matrix used in this first experiment. Despite the pressure doubling, small gaskets were formed during the run. Normally, higher loads result in higher pressures inside the cube and more material flows out to form long thin gaskets. Consequently, it is surprising that higher loads and much higher pressures result in much smaller and shorter gaskets at first glance. The key to the observation is the change of the whole cube deformation because of the internal second-stage anvil configuration.

We also performed an ultrasonic interferometry measurement using "multistaging." To increase the reflection area, the diameter of the sample space in the matrix and the diameter of the subanvil's front face was increased to $1.7 \mathrm{~mm}$. The top subanvil was acoustically coupled to MAX80's upper anvil by a platinum disk of the same diameter as the cylindrical shaft of the subanvil. From an acoustical point of view, the travel path has three buffer rods - top MAX80 anvil, platinum disk, upper internal opposed anvil— and the bottom internal opposed anvil as reflector (compare figure Fig. 19). As a result of preparatory experiments, we had found that the upper cutoff frequency for the existing transducer-tungsten carbide anvil system was $\sim 300 \mathrm{MHz}$. An excitation function representing the bandwidth of $100-300 \mathrm{MHz}$ was calculated and used in the experiment (Fig. 21). Under high-pressure conditions, we were able to detect ultrasonic energy reflected at the interfaces of the $\mathrm{NaCl}$ sample

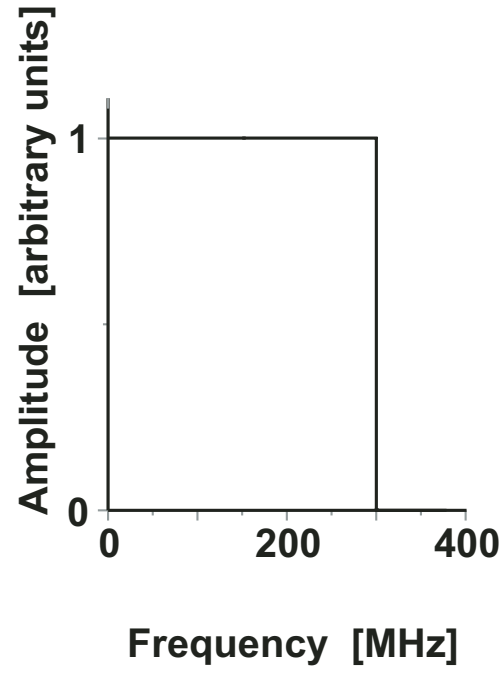

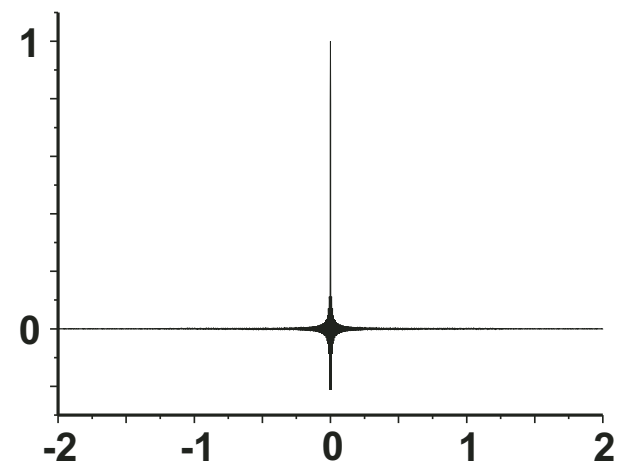

Time [ $\mu s]$

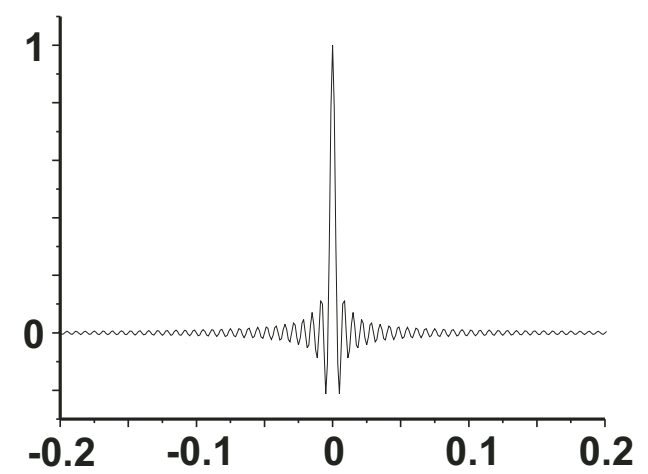

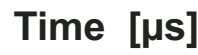

\footnotetext{
A

B

Figure 21. Excitation function representing the frequency range 100-300 MHz for "multistaging" ultrasonic interferometry in time and spatial domain. The smaller sample requires higher frequencies. (A) Frequency band pass of the calculated excitation function in frequency domain. (B) Calculated excitation function of $4 \mathrm{~s}$ duration in time domain. (C) Central part of the excitation function shown in B displayed with $10 \times$ higher time resolution $(0.4 \mu \mathrm{s})$ in time domain.
} 
as the fundamental condition for interferometric data evaluation, which is in accordance with previously published data for single-stage experiments (Mueller et al., 2005a, 2005b).

\section{Transient Measurements: Quartz to Coesite Transition}

The high-pressure $\mathrm{SiO}_{2}$ polymorph coesite is an important mineral in the subduction process, including in crustal material as has been observed in rocks of the Dora Maira Massif (western Alps) by Chopin (1984), Gillet et al. (1984), and also in other subducted continental rocks (Schreyer, 1995). The quartz to coesite transition is thus of fundamental importance in the effort to understand the processes within subducting lithosphere. Furthermore, the nature of the quartz to coesite transition is controversial, because highpressure XRD studies suggest an intermediate phase during the transformation process (Bourret et al., 1986; Heaney and Veblen, 1991; Zinn et al., 1997a, 1997b; Prakapenka et al., 2004).

We used natural fine-grained quartzite with a $\mathrm{SiO}_{2}$ content of more than $99 \mathrm{wt} \%$ (Schilling, 1999) for the experiments. The samples were shaped to cylinders of $2.4 \mathrm{~mm}$ diameter and $1.6 \mathrm{~mm}$ length and $2.0 \mathrm{~mm}$ diameter and $1.2 \mathrm{~mm}$ length, respectively, using a high-precision cylindrical grinding machine. Both end faces were polished for optimum ultrasonic coupling. Figure 22 shows the results for the elastic-wave velocities using $8 \mathrm{~mm}$ as well as $6 \mathrm{~mm}$ boron epoxy cubes. A minimum pressure of 4.5 $\mathrm{GPa}$ was applied to observe the phase transition from quartz to coesite. At $800{ }^{\circ} \mathrm{C}$, it took place in less than $2 \mathrm{~min}$, much too fast for the classical sweep technique. If the frequency span is reduced and the number of steps is minimized, the variation in elastic properties during the phase transition could be observed at temperatures between $720^{\circ} \mathrm{C}$ and $750{ }^{\circ} \mathrm{C}$. At lower temperatures, the transition did not take place at all or stopped at $\sim 50 \%$ transformation. The temperature-induced weakening of the boron epoxy cube resulted in a stress release in the whole high-pressure cell. Together with the phase transition-induced volume reduction of the sample, a dramatic pressure decrease occurred that could not be compensated by increasing the load of the press. The pressure measurement was performed using the X-ray diffraction from the $\mathrm{NaCl}$ pressure marker also used as ultrasonic reflector.

To perform experiments at higher pressures, we used a setup for $6 \mathrm{~mm}$ boron epoxy cubes and $4 \mathrm{~mm}$ anvil truncation. Furthermore, we used gasket insets (Mueller et al., 2003, 2005a) to support the cubes. In Figure 22, the variation of compressional and shear-wave velocities, $V_{\mathrm{p}}$ and $V_{\mathrm{s}}$, during the quartz to coesite phase transformation is shown.

Figure 23 compares the $V_{\mathrm{p}}$ data and the results of the $\mathrm{X}$-ray diffraction measurements performed simultaneously. It demonstrates the first transient ultrasonic interferometry technique. The measurement was accelerated by limiting the frequency span to a little more than $2 \mathrm{MHz}$ and using a frequency step of $300 \mathrm{kHz}$. The observed peak shift corresponds to an increase of $V_{\mathrm{p}}$ from $\sim 6.5 \mathrm{~km} / \mathrm{s}$ to $\sim 7.5 \mathrm{~km} / \mathrm{s}$ with some indication of an intermediate state. Corresponding DTF measurements are in progress.

\section{Multi-Cycle Experiments: Clinoenstatite}

One of the most challenging recent tasks for mineral physics has been the investigation of unquenchable phase transitions. As an interesting example, we measured the elasticwave velocities at the high-pressure clinoenstatite $\left(\mathrm{MgSiO}_{3}\right)$ to low-pressure clinoenstatite transition under high-pressure and high-temperature conditions in conjunction with in situ XRD. For ultrasonic interferometry experiments, low-pressure clinoenstatite powder synthesized at ambient pressure was hotisostatic-pressed (HIP) (Liebermann et al., 1975) at $0.4 \mathrm{GPa}$ and $1400{ }^{\circ} \mathrm{C}$ for $2 \mathrm{~h}$ in MAX80 to obtain minimum-porosity samples. The elastic-wave velocities, $V_{\mathrm{p}}$ and $V_{\mathrm{s}}$, of the clinoenstatite sample were measured in situ using the sweep as well as the DTF technique (Mueller et al., 2005b).

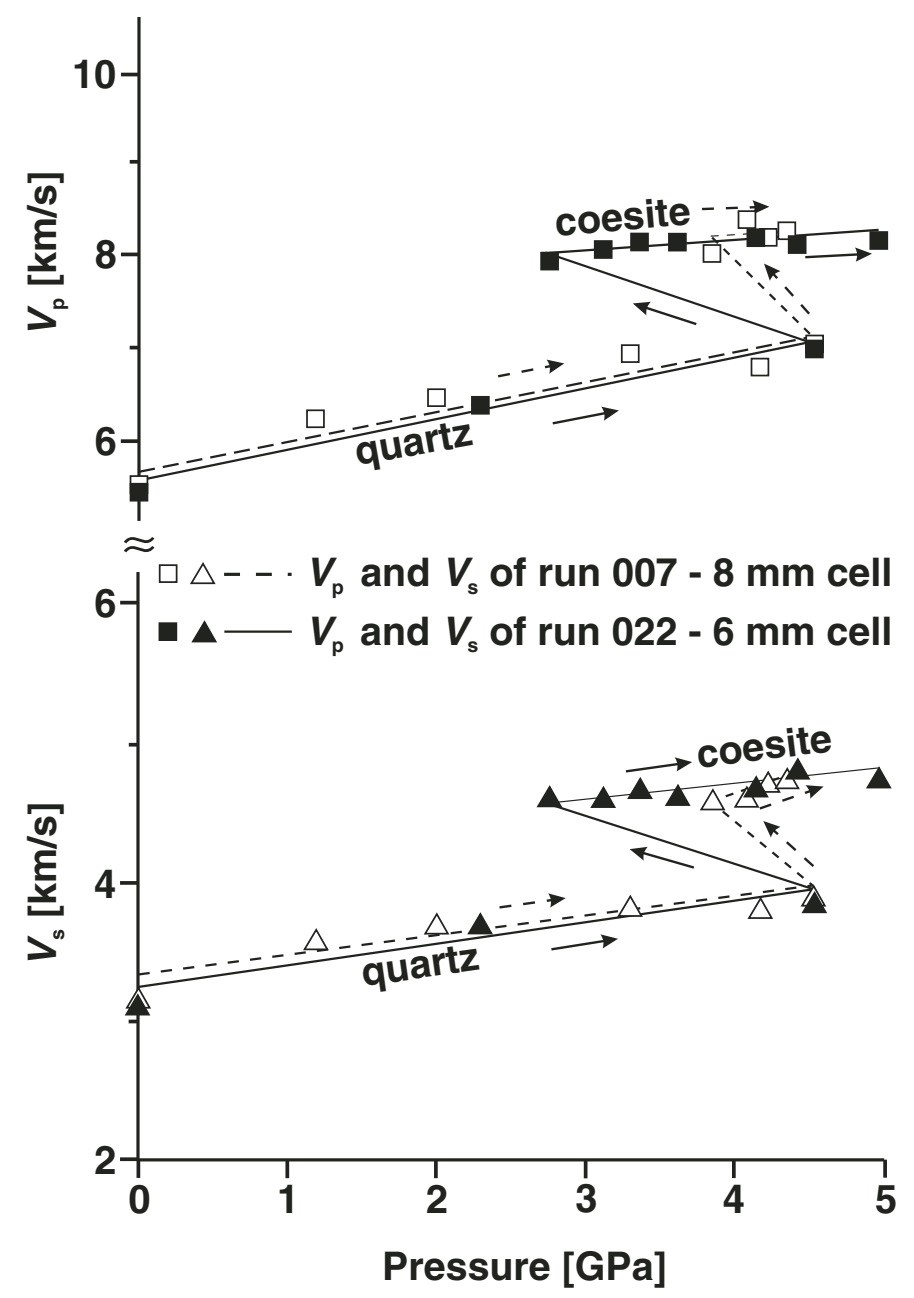

Figure 22. MAX80 $V_{\mathrm{p}}$ and $V_{\mathrm{s}}$ for quartz and coesite using $8 \mathrm{~mm}$ and $6 \mathrm{~mm}$ cubes. The pressure drop during the phase transformation to coesite is the result of stress release in the cell assembly by increasing temperature and also of the volume reduction of the sample. The uncertainty of the interferometric $V_{\mathrm{p}}$ and $V_{\mathrm{s}}$ measurement is $<1 \%$, i.e., smaller than the symbol size. 
A
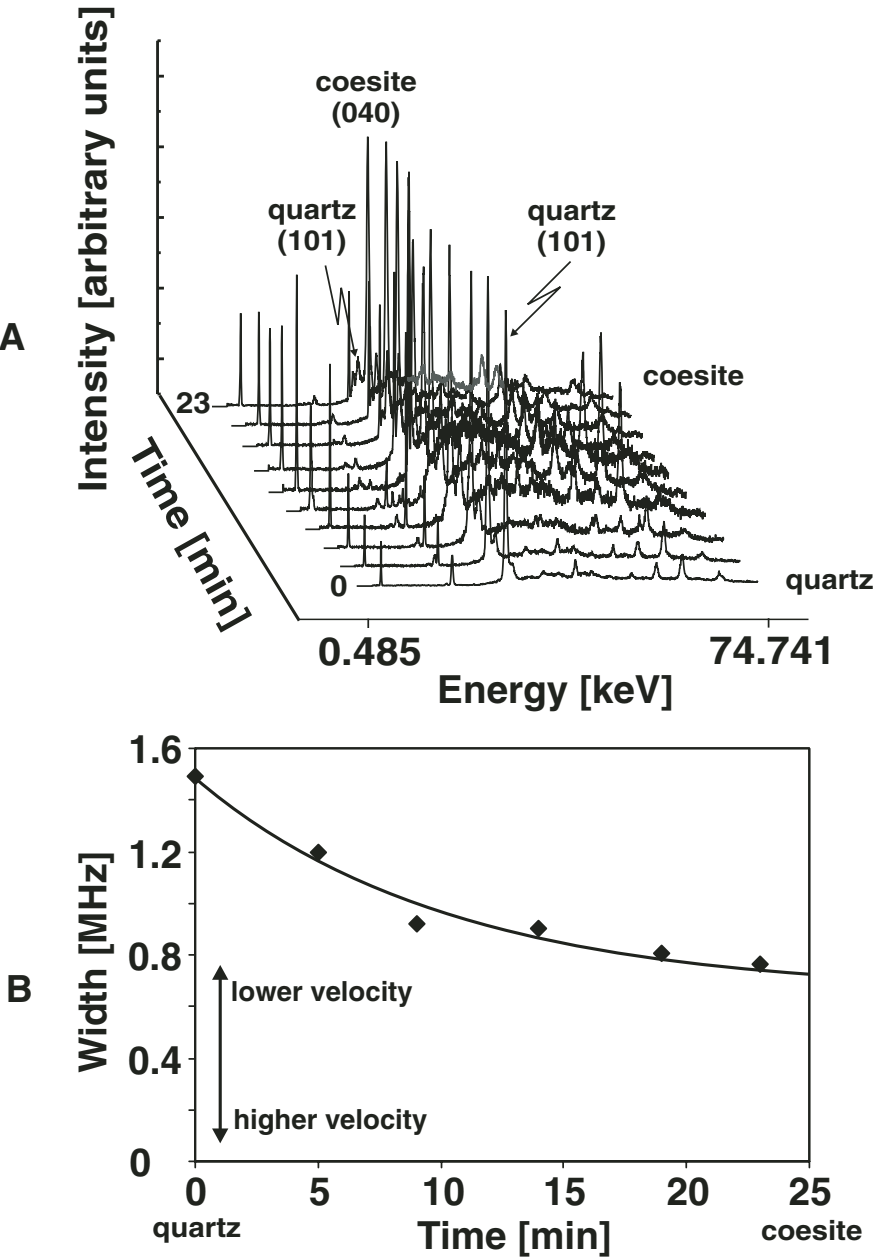

Figure 23. MAX80 transient measurements at the quartz to coesite transition. (A) Transient X-ray diffraction (XRD) patterns. (B) Transient measurement of compressional wave traveltime. The width is the distance between adjacent maxima and minima of the interference pattern of the echoes from both sample front faces. These maxima and minima represent the frequencies of constructive and destructive interference. The width is a measure of the traveltime inside the sample.

First we carried out ultrasonic experiments in a prograde manner, i.e., pressure and temperature were increased during the measurements. Kung et al. (2004) described and explained the opposite strategy, because otherwise the measured phase boundaries were apparently shifted due to the unreleased stress inside minimum-porosity samples as used in ultrasonic experiments. Therefore, we also performed an experiment in retrograde manner. Figure 24 illustrates the $P-T$ paths of our experiments in the phase diagram of $\mathrm{MgSiO}_{3}$ (Angel and HughJones, 1994; Mueller et al., 2005b).

Figure 25 summarizes the measured ultrasonic wave velocities of two experiments. After prograde crossing the phase boundary at $6.4 \mathrm{GPa}$, the temperature was further increased up to $700{ }^{\circ} \mathrm{C}$ to rule out crossing the phase boundary to high-pressure clinoenstatite during the following pressure increase up to

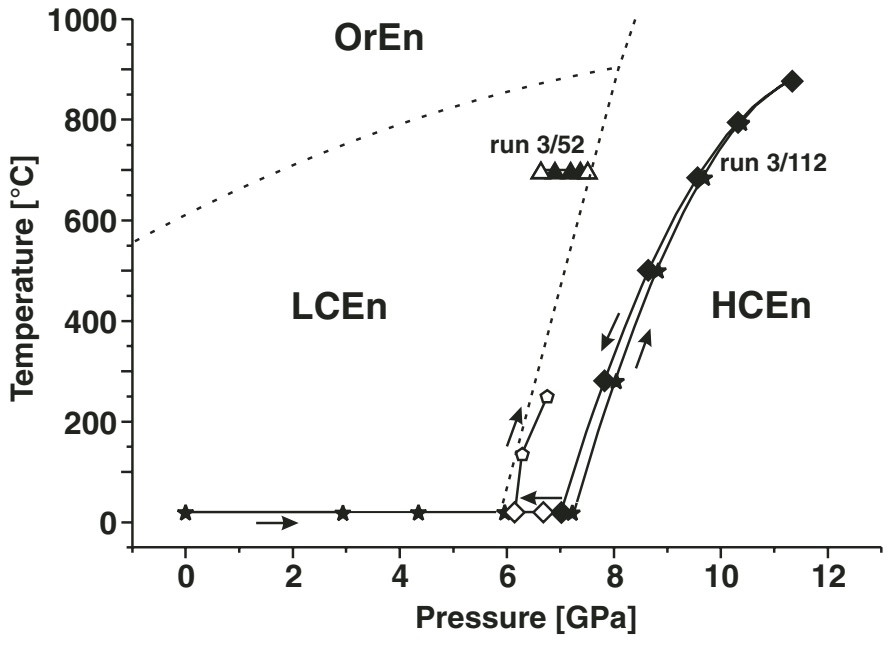

Figure 24. MAX80 pressure-temperature $(P-T)$ paths for ultrasonic measurements with clinoenstatite $\left(\mathrm{MgSiO}_{3}\right.$, high-pressure clinoenstatite [HCEn] and low-pressure clinoenstatite [LCEn]). First hot-isostaticpressed low-pressure clinoenstatite is transformed to high-pressure clinoenstatite (solid stars) by increasing the pressure. The temperature is increased by $1 \mathrm{~K} / \mathrm{min}$ to release the stress. The thermal expansion further increases the pressure (solid stars). Next, the temperature is decreased by $1 \mathrm{~K} / \mathrm{min}$ (solid diamonds). The next phase is the pressure decrease down to $\sim 6 \mathrm{GPa}$ at normal temperature (open diamonds). Now, the next temperature cycle is started (open pentagons). Run 3/52 aims at the velocity dependence of low-pressure clinoenstatite on pressure at constant temperature of $700{ }^{\circ} \mathrm{C}$ performed with sweep (solid triangles) and data transfer function (DTF) (open triangles) techniques. OrEn —orthoenstatite.

7.5 GPa. Run 3/52 aimed at the velocity dependence on pressure at constant temperature of $700{ }^{\circ} \mathrm{C}$. For $V_{\mathrm{p}}$ and $V_{\mathrm{s}}$ velocity determinations, the pressure derivatives at $700^{\circ} \mathrm{C}$ of $0.8 \mathrm{~km} /(\mathrm{s} \mathrm{GPa})$ and $0.7 \mathrm{~km} /(\mathrm{s} \mathrm{GPa})$ were determined for low-pressure clinoenstatite, respectively. The measurements were performed using the sweep technique at both pressure levels and the DTF technique also at these points and in between. The results demonstrate a good correspondence of both techniques (Mueller et al., 2005b).

Run 3/112 was a multicycle retrograde experiment in the high-pressure clinoenstatite stability field. After increasing the pressure up to $7.2 \mathrm{GPa}$, the temperature was increased by $1 \mathrm{~K}$ per minute up to $875^{\circ} \mathrm{C}$. As a result of thermal expansion, the pressure increased up to $11.3 \mathrm{GPa}$ ("thermal pressure"). After this, the temperature was reduced with the same low negative temperature increment. The ultrasonic measurements were performed during this second segment of the experiment. The results show the combined $P-T$ dependence along the path shown in Figure 24. After reaching room temperature, the pressure was released down to $6.1 \mathrm{GPa}$. During this segment $V_{\mathrm{p}}$ and $V_{\mathrm{s}}$ dependence on pressure at normal temperature was measured for a stress-released sample. The pressure derivatives for high-pressure clinoenstatite at normal temperature were determined to be $0.089 \mathrm{~km} /(\mathrm{s} \mathrm{GPa})$ for $V_{\mathrm{p}}$ and $0.02 \mathrm{~km} /(\mathrm{s} \mathrm{GPa})$ for $V_{\mathrm{s}}$, respectively. The results correspond well with the data of Kung et al. (2004) for high-pressure clinoenstatite. After this segment, the next temperature cycle with 


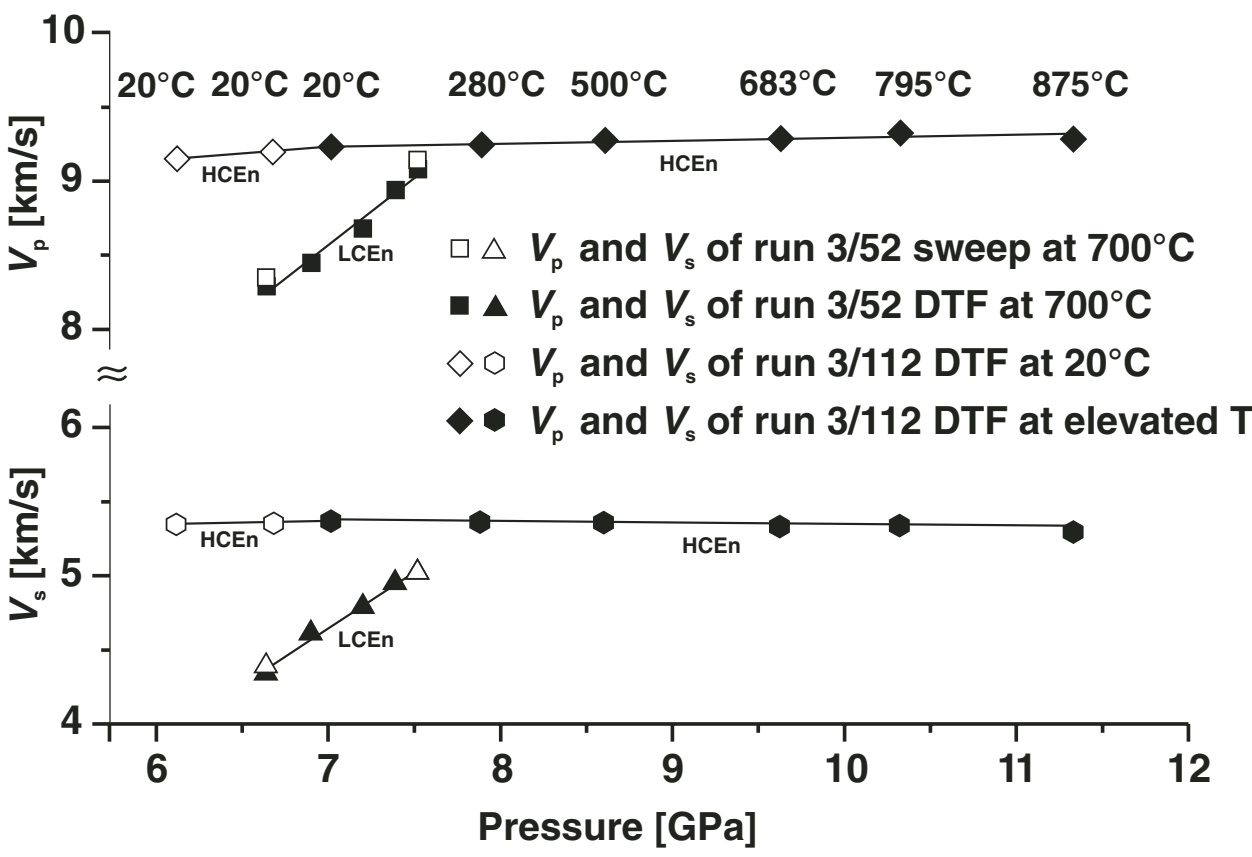

Figure 25. MAX80 compressional and shear-wave velocities, $V_{\mathrm{p}}$ and $V_{\mathrm{s}}$, in clinoenstatite at various pressure and temperature conditions (hot isostatic pressed [HIP] sample). Because of the pressure-temperature $(P-T)$ path shown in Figure 24, the results for high-pressure clinoenstatite represent the combined $P-T$ effect on velocities, contrary to the pure $P$ influence in the low-pressure clinoenstatite data. The uncertainty of the interferometric $V_{\mathrm{p}}$ and $V_{\mathrm{s}}$ measurement is $<1 \%$, i.e., smaller than the symbol size. DTF - data transfer function; HCEn-high-pressure clinoenstatite; LCEn-low-pressure clinoenstatite.

$2 \mathrm{~K}$ per minute was launched. The slightly higher temperature increment was acceptable for all further cycles because the sample was almost completely stress-released after the first cycle. The slow pressure release did not indicate remarkable new stress inside the sample. Figure 26 shows the pressure-induced length decrease of a clinoenstatite sample monitored by X-radiography.

The low-pressure to high-pressure clinoenstatite phase transition might be an important reaction in deeper parts of cold, fast subducting slabs. Because of high subduction velocity, the temperature increase is retarded, i.e., high-pressure clinoenstatite keeps stable at much deeper levels than under temperatureequilibrium conditions. If the phase transition takes place at greater depths yet, the higher $V_{\mathrm{p}}$ and $V_{\mathrm{s}}$ pressure derivatives of low-pressure clinoenstatite might result in a greater velocity drop than the published $0.5 \%$ (Kung et al., 2004; Mueller et al., 2005a). Another aspect is the influence on the rheology of downgoing slabs by transformation plasticity (e.g., Poirier, 1982; Schmidt et al., 2003) of clinoenstatite-bearing rocks (Mueller et al., 2005a).

\section{SUMMARY}

The data demonstrate the potentials and technical details of two multianvil apparatus for the experimental simulation of Earth's mantle conditions installed at HASYLAB-DESY,

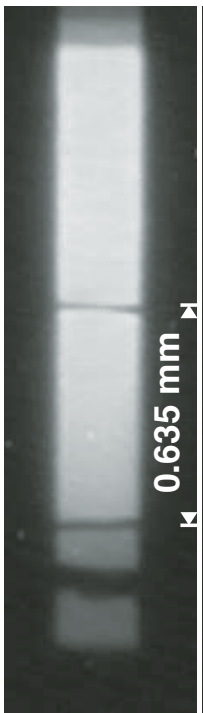

$0.55 \mathrm{GPa}$

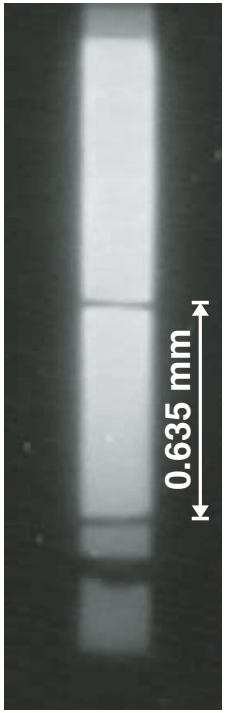

$1.1 \mathrm{GPa}$

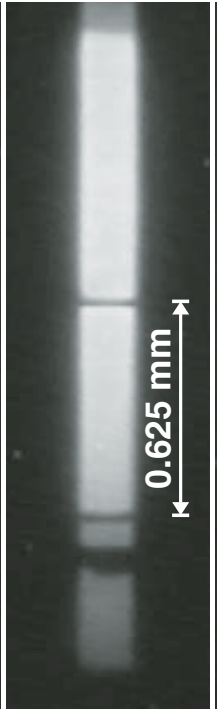

4.1 GPa

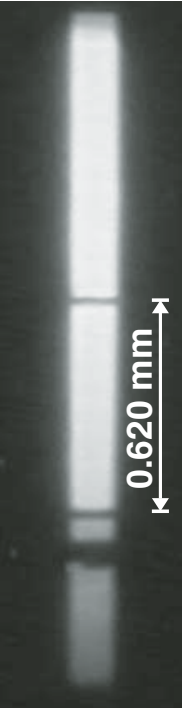

$5.2 \mathrm{GPa}$

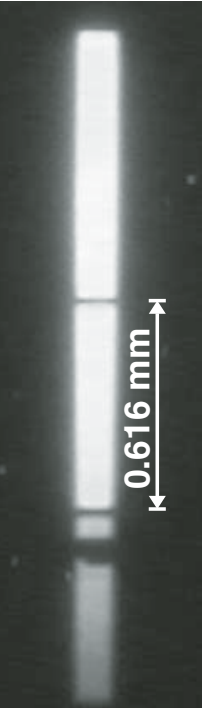

$7.5 \mathrm{GPa}$

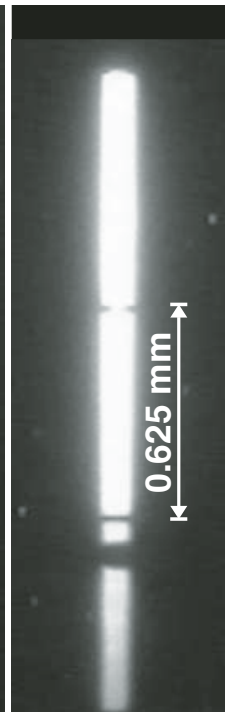

$7.5 \mathrm{GPa}$ $210^{\circ} \mathrm{C}$
Figure 26. Pressure-induced length decrease of a clinoenstatite sample monitored by $\mathrm{X}$-radiography under in situ conditions. The sample length is measured by image processing of the shadow graphs, i.e., the number of pixels between the two dark markers (Au foil) is measured. The pixel size is determined from a calibration with known sample length at ambient conditions. For further details, compare with Figure 5. The decreasing width of the shadow graphs is the result of the decreasing gap between the anvils at increasing pressure. 
Hamburg-MAX80 and MAX200x. Besides the synchrotron radiation techniques, XRD and X-radiography, different ultrasonic interferometry methods are described. With respect to future scientific challenges and present-day technological feasibility, we described approaches to new techniques and presented the most recent results.

\section{ACKNOWLEDGMENTS}

We would like to express our special thanks to the editor E. Ohtani for his initiative, guidance, and patience. Our special thanks are due to Y. Wang and $\mathrm{B}$. Li, without their helpful and fruitful discussions, the demonstrated development would have been much less successful. The constructive reviews of two unknown referees, which substantially improved the paper, are gratefully acknowledged. We also acknowledge the kind guidance and the support of B. Liebermann, D. Weidner, and M. Vaughan. We are especially grateful to S. Ganschow for the Ce:YAG crystal, manufactured and put at our disposal by IKZ, and J. Kulesza (ADC) for his untiring support. The authors are particularly indebted to B. Wunder for sample courtesy, S. Speziale for looking through the manuscript, M. Kreplin for the special preparation, N. Heidbrook, H. Zink, J. Novak, and O. Beimgraben (DESY) for their kind assistance, as well as all colleagues of the high-pressure mechanical workshop for their dedicated support.

\section{REFERENCES CITED}

Angel, R.J., and Hugh-Jones, D.A., 1994, Equations of state and thermodynamic properties of enstatite pyroxenes: Journal of Geophysical Research, v. 99, p. 19,777-19,783, doi: 10.1029/94JB01750.

Beckmann, F., Lippmann, T., Metge, J., Martins, R.V., Dose, T., and Schreyer, A., 2003, HARWI-II Material Science Beamline: HASYLAB Annual Report 2003, p. 139-142.

Birch, F., 1960, The velocity of compressional waves in rocks to 10 kilobars. Part 1: Journal of Geophysical Research, v. 65, p. 1083-1102.

Birch, F., 1961, The velocity of compressional waves in rocks to 10 kilobars. Part 2: Journal of Geophysical Research, v. 66, p. 2199-2224.

Bolfan-Casanova, N., Keppler, H., and Rubie, D.C., 1997, Distribution of water between lower mantle phases; $\mathrm{MgSiO}_{3}$-ilmenite, $\mathrm{MgSiO}_{3}$-perovskite and stishovite: Eos (Transactions, American Geophysical Union), v. 78, p. 736.

Bolfan-Casanova, N., Keppler, H., and Rubie, D.C., 1998, Partitioning of water between high pressure phases in the system $\mathrm{MgSiO}_{3}+0.5$ wt.\% $\mathrm{H}_{2} \mathrm{O}$ : Min. Magazine, v. 62A, Part 1, p. 185-186.

Bolfan-Casanova, N., Mackwell, S., Keppler, H., McCammon, C., and Rubie, D.C., 2002, Pressure dependence of $\mathrm{H}$ solubility in magnesiowuestite up to $25 \mathrm{GPa}$; implications for the storage of water in the Earth's lower mantle: Geophysical Research Letters, v. 29, 1449, doi: 10.1029/2001GL014457.

Bourret, A., Hinze, E., and Hochheimer, H.D., 1986, Twin structure in coesite studied by high resolution electron microscopy: Physics and Chemistry of Minerals, v. 13, p. 206-212, doi: 10.1007/BF00308163.

Chopin, C., 1984, Coesite and pure pyrope in high-grade blueschists of the western Alps; a first record and some consequences: Contributions to Mineralogy and Petrology, v. 86, p. 107-118, doi: 10.1007/BF00381838.

Decker, D.L., 1971, High-pressure equation of state for $\mathrm{NaCl}, \mathrm{KCl}$, and CsCl: Journal of Applied Physics, v. 42, p. 3239-3244, doi: $10.1063 / 1.1660714$.

Fujisava, H., and Ito, E., 1984, Measurements of ultrasonic wave velocities in solids under high pressure, in Proceedings of the 4th Symposium on Ultrasonic Electronics: Tokyo, Japan (1983): Journal of Applied Physics, Supplement 23-1, p. 51-53.
Fujisava, H., and Ito, E., 1985, Measurements of ultrasonic wave velocities of tungsten carbide as a standard material under high pressure up to $8 \mathrm{GPa}$, in Proceedings of the 5th Symposium on Ultrasonic Electronics: Tokyo, Japan (1984): Journal of Applied Physics, Supplement 24-1, p. $103-105$.

Funamori, N., Yagi, T., Utsumi, W., Kondo, T., Uchida, Y., and Funamori, M., 1996, Thermoelastic properties of $\mathrm{MgSiO}_{3}$ perovskite determined by in-situ X-ray observations up to $30 \mathrm{GPa}$ and $2000 \mathrm{~K}$ : Journal of Geophysical Research, B, Solid Earth and Planets, v. 101, p. 8257-8269, doi: 10.1029/95JB03732.

Gillet, P., Ingrin, J., and Chopin, C., 1984, Coesite in subducted continental crust; $P$ - $T$ history deduced from an elastic model: Earth and Planetary Science Letters, v. 70, p. 426-436, doi: 10.1016/0012-821X(84)90026-8.

Heaney, P.J., and Veblen, D.R., 1991, Observations of the $\alpha-\beta$ phase transition in quartz: A review of imaging and diffraction studies and some new results: The American Mineralogist, v. 76, p. 1018-1032.

Hinze, E., Kremmler, J., and Lauterjung, J., 1991, Viel-Stempel-Hochdruckapparatur für Pulverdiffraktometrie mit Synchrotronstrahlung (in German): Deutsches ElektronenSYnchrotron (DESY), Jahresreport 1991.

Hinze, E., Kremmler, J., and Lauterjung, J., 1992, Mehrstempel-Hochdruckapparatur für Pulverdiffraktometrie unter geowissenschaftlich relevanten Bedingungen, MAX-80 (in German), Förderung der Grundlagenforschung durch den Bundesminister für Forschung und Technologie, Ergebnisberichte 1989-1992, Erforschung kondensierter Materie und Atomphysik im Verbund mit Großgeräten: Physik-Chemie-Biologie, Band II, Festkörperphysik und Materialforschung, p. 84-88.

Huppertz, H., 2003, Multianvil High-Pressure/High-Temperature Syntheses in Solid State Chemistry: Dresden, Hochdruck-Workshop.

Ito, E., Katsura, T., Aizawa, Y., Kawabe, K., Yokoshi, S., Kubo, A., Nozawa, A., and Funakoshi, K., 2005, High-pressure generation in the Kawaitype apparatus equipped with sintered diamond anvils: Application to the wurtzite-rocksalt transformation in GaN, in Chen, J., Wang, Y., Duffy, T., Shen, G., and Dobrzhinetskaya, L., eds., Advances in High Pressure Technology for Geophysical Application: Amsterdam, Elsevier Besloten Vennootschap, p. 451-460.

Jamieson, J.C., Fritz, J.N., and Manghnani, M.H., 1982, Pressure measurement at high temperature in X-ray diffraction studies: Gold as a primary standard, in Akimoto, S., and Manghnani, M.H., eds., High Pressure Research in Geophysics: Tokyo, Center for Academic Publications, p. 27-47.

Katsura, T., Funakoshi, K., Kubo, A., Nishiyama, N., Tange, Y., Sueda, Y., Kubo, T., and Utsumi, W., 2004, A large-volume high $P$-T apparatus for in situ X-ray observation "SPEED-MkII": Physics of the Earth and Planetary Interiors, v. 143-144, p. 497-506, doi: 10.1016/j.pepi.2003.07.025.

Kinoshita, H., Hamaya, N., and Fujisava, H., 1979, Elastic properties of singlecrystal $\mathrm{NaCl}$ under high pressures to 80 kbar: Journal of Physics of the Earth, v. 27, p. 337-350.

Kohlstedt, D.L., Keppler, H., and Rubie, D.C., 1994a, Solubility of water in $\alpha-$, $\beta-$ and $\gamma-(\mathrm{Mg}, \mathrm{Fe})_{2} \mathrm{SiO}_{4}$ at high pressures: Eos (Transactions, American Geophysical Union), v. 75 , p. 652.

Kohlstedt, D.L., Rubie, D.C., and Keppler, H., 1994b, Experimental constraints on the solubility of water in upper mantle minerals: Terra Abstracts, v. 6, suppl. 1, p. 29.

Kohlstedt, D.L., Keppler, H., and Rubie, D.C., 1996, Solubility of water in the $\alpha, \beta$ and $\gamma$ phases of $(\mathrm{Mg}, \mathrm{Fe})_{2} \mathrm{SiO}_{4}$ : Contributions to Mineralogy and Petrology, v. 123, p. 345-357, doi: 10.1007/s004100050161.

Kondo, T., Sawamoto, H., Yoneda, A., Kato, M., Matsumuro, A., Yagi, T., and Kikegawa, T., 1993a, The use of sintered diamond anvils in the MA8 type high-pressure apparatus: PAGEOPH, v. 141, p. 601-611, doi: 10.1007/ BF00998347.

Kondo, T., Sawamoto, H., Yoneda, A., Kato, M., Matsumuro, A., and Yagi, T., 1993b, Ultrahigh-pressure and high temperature generation by use of the MA8 system with sintered diamond anvils: High Temperatures, High Pressures, v. 25, p. 105-112.

Kung, J., Li, B., Uchida, T., Wang, Y., Neuville, D., and Liebermann, R.C., 2004, In situ measurements of sound velocities and densities across the orthopyroxene $\rightarrow$ high-pressure clinopyroxene transition in $\mathrm{MgSiO}_{3}$ at high pressure: Physics of the Earth and Planetary Interiors, v. 147, p. $27-$ 44, doi: 10.1016/j.pepi.2004.05.008.

Leinenweber, K., 2005, Designing multi-anvil assemblies: The COMPRES cell assembly project: Argonne, Advanced Photon Source, COMPRES MultiAnvil Workshop. 
Li, B., Liebermann, R.C., and Jackson, I., 1994, Measurements of elastic wave velocity of polycrystal $\mathrm{Al}_{2} \mathrm{O}_{3}$ to $10 \mathrm{GPa}$ : Eos (Transactions, American Geophysical Union), v. 75, p. 596

Li, B., Liebermann, R.C., Gwanmesia, G.D., and Jackson, I., 1995a, Elastic wave velocities of mantle minerals to $10 \mathrm{GPa}$ in multi-anvil apparatus by in situ ultrasonic techniques: Eos (Transactions, American Geophysical Union), v. 76, p. 277.

Li, B., Gwanmesia, G.D., and Liebermann, R.C., 1995b, Elastic wave velocity of olivine and beta polymorphs of $\mathrm{Mg}_{2} \mathrm{SiO}_{4}$ at transition zone pressures: Eos (Transactions, American Geophysical Union), v. 76, p. 619.

Li, B., Rigden, S.M., and Liebermann, R.C., 1996a, Elasticity of stishovite at high pressure: Physics of the Earth and Planetary Interiors, v. 96, p. 113127, doi: 10.1016/0031-9201(96)03144-5.

Li, B., Jackson, I., Gasparik, T., and Liebermann, R.C., 1996b, Elastic wave velocity measurement in multi-anvil apparatus to $10 \mathrm{GPa}$ using ultrasonic interferometry: International Union of Geodesy and Geophysics XXI Special Volume: Physics of the Earth and Planetary Interiors, v. 98, p. 79-91, doi: 10.1016/S0031-9201(96)03173-1.

Li, B., Gwanmesia, G.D., and Liebermann, R.C., 1996c, Sound velocities of olivine and beta polymorphs of $\mathrm{Mg}_{2} \mathrm{SiO}_{4}$ at Earth's transition zone pressures: Geophysical Research Letters, v. 23, p. 2259-2262, doi: 10.1029/96GL02084.

Li, B., Chen, G., Gwanmesia, G.D., and Liebermann, R.C., 1998, Sound velocity measurements at mantle transition zone conditions of pressure and temperature using ultrasonic interferometry in a multianvil apparatus, in Manghnani, M.H., and Yagi, T., eds., Properties of Earth and Planetary Materials at High Pressure and Temperature: American Geophysical Union Geophysical Monograph 101, p. 41-61.

Li, B., Vaughan, M.T., Kung, J., and Weidner, D.J., 2001, Direct length measurement using X-radiography for the determination of acoustic velocities at high pressure and temperature: NSLS (National Synchrotron Light Source) Activity Report 2001, p. 2-103-2-106.

Li, B., Chen, K., Kung, J., Liebermann, R.C., and Weidner, D.J., 2002, Sound velocity measurement using transfer function method: Journal of Physics Condensed Matter, v. 14, p. 11,337-11,342, doi: 10.1088/0953$8984 / 14 / 44 / 478$

Li, B., Kung, J., and Liebermann, R.C., 2004, Modern techniques in measuring elasticity of Earth materials at high pressure and high temperature using ultrasonic interferometry in conjunction with synchrotron X-radiation in multi-anvil apparatus: Physics of the Earth and Planetary Interiors, v. 143-144, p. 559-574, doi: 10.1016/j.pepi.2003.09.020.

Li, B., Kung, J., Uchida, T., and Wang, Y., 2005, Simultaneous equation of state, pressure calibration and sound velocity measurements to lower mantle pressures using multi-anvil apparatus, in Chen, J., Wang, Y., Duffy, T., Shen, G., and Dobrzhinetskaya, L., eds., Advances in High Pressure Technology for Geophysical Application: Amsterdam, Elsevier Besloten Vennootschap, p. 49-66.

Liebermann, R.C., Ringwood, A.E., Mayson, D.J., and Major, A., 1975, Hotpressing of polycrystalline aggregate at very high pressure for ultrasonic measurements, in Osugi, J., ed., Proceedings of the 4th conference on High Pressure: Tokyo, Physico-Chemical Society of Japan, p. 495-502.

Liebermann, R.C., Prewitt, T.C., and Weidner, D.J., 1985, Large-volume highpressure mineral physics in Japan: Eos (Transactions, American Geophysical Union), v. 66, p. 138.

Litasov, K., and Ohtani, E., 2003a, Stability of various hydrous phases in CMAS pyrolite- $\mathrm{H}_{2} \mathrm{O}$ system up to $25 \mathrm{GPa}$ : Physics and Chemistry of Minerals, v. 30, p. 147-156, doi: 10.1007/s00269-003-0301-y.

Litasov, K., and Ohtani, E., 2003b, Hydrous solidus of CMAS-pyrolite and melting of mantle plumes at the bottom of the upper mantle: Geophysical Research Letters, v. 30, p. 2143, doi: 10.1029/2003GL018318.

Litasov, K., and Ohtani, E., 2005, Phase relations in hydrous MORB at 18$28 \mathrm{GPa}$ : Implications for heterogeneity of the lower mantle: Physics of the Earth and Planetary Interiors, v. 150, p. 239-263, doi: 10.1016/ j.pepi.2004.10.010.

Litasov, K., Ohtani, E., Langenhorst, F., Yurimoto, H., Kubo, T., and Kondo, T., 2003, Water solubility in Mg-perovskites and water storage capacity in the lower mantle: Earth and Planetary Science Letters, v. 211, p. 189-203, doi: 10.1016/S0012-821X(03)00200-0.

Litasov, K., Ohtani, E., Suzuki, A., Kawazoe, T., and Funakoshi, K., 2004, Absence of density crossover between basalt and peridotite in the cold slabs passing through $660 \mathrm{~km}$ discontinuity: Geophysical Research Letters, v. 31, L24607, doi: 10.1029/2004GL021306.
McSkimin, H.J., 1950, Ultrasonic measurement techniques applicable to small solid specimens: The Journal of the Acoustical Society of America, v. 22, p. 413-418, doi: 10.1121/1.1906618.

Mueller, H.J., Lauterjung, J., Schilling, F.R., Lathe, C., and Nover, G., 2002, Symmetric and asymmetric interferometric method for ultrasonic compressional and shear wave velocity measurements in piston-cylinder and multi-anvil high-pressure apparatus: European Journal of Mineralogy, v. 14, p. 581-589, doi: 10.1127/0935-1221/2002/0014-0581.

Mueller, H.J., Schilling, F.R., Lauterjung, J., and Lathe, C., 2003, A standard free pressure calibration using simultaneous XRD and elastic property measurements in a multi-anvil device: European Journal of Mineralogy, v. 15, p. 865-873, doi: 10.1127/0935-1221/2003/0015-0865.

Mueller, H.J., Lathe, C., and Schilling, F.R., 2005a, Simultaneous determination of elastic and structural properties under simulated mantle conditions using multi-anvil device MAX80, in Chen, J., Wang, Y., Duffy, T., Shen, G., and Dobrzhinetskaya, L., eds., Advances in High Pressure Technology for Geophysical Application: Amsterdam, Elsevier Besloten Vennootschap, p. 67-94.

Mueller, H.J., Schilling, F.R., Lathe, C., and Lauterjung, J., 2005b, Calibration based on a primary pressure scale in a multi-anvil device, in Chen, J., Wang, Y., Duffy, T., Shen, G., and Dobrzhinetskaya, L., eds., Advances in High Pressure Technology for Geophysical Application: Amsterdam, Elsevier Besloten Vennootschap, p. 427-449.

Ohtani, E., and Maeda, M., 2001, Density of basaltic melt at high pressure and stability of the melt at the base of the lower mantle: Earth and Planetary Science Letters, v. 193, p. 69-75, doi: 10.1016/S0012-821X(01)00505-2.

Ohtani, E., Mizobata, H., and Yurimoto, H., 2000, Stability of dense hydrous magnesium silicate phases in the systems $\mathrm{Mg}_{2} \mathrm{SiO}_{4}-\mathrm{H}_{2} \mathrm{O}$ and $\mathrm{MgSiO}_{3}$ $\mathrm{H}_{2} \mathrm{O}$ at pressures up to $27 \mathrm{GPa}$ : Physics and Chemistry of Minerals, v. 27 , p. 533-544, doi: $10.1007 / \mathrm{s} 002690000097$.

Ohtani, E., Toma, M., Litasov, K., Kubo, T., and Suzuki, A., 2001a, Stability of dense hydrous magnesium silicate phases and water storage capacity in the transition zone and lower mantle: Physics of the Earth and Planetary Interiors, v. 124, p. 105-117, doi: 10.1016/S0031-9201(01)00192-3.

Ohtani, E., Litasov, K., Suzuki, A., and Kondo, T., 2001b, Stability field of new hydrous phase, $\delta$-AlOOH, with implications for water transport into the deep mantle: Geophysical Research Letters, v. 28, p. 3991-3993, doi: 10.1029/2001GL013397.

Ohtani, E., Toma, M., Kubo, T., Kondo, T., and Kikegawa, T., 2003, In situ X-ray observation of decomposition of superhydrous phase B at high pressure and temperature: Geophysical Research Letters, v. 30, p. 1029, doi: 10.1029/2002GL015549.

Ohtani, E., Litasov, K., Hosoya, T., Kubo, T., and Kondo, T., 2004, Water transport into the deep mantle and formation of a hydrous transition zone: Physics of the Earth and Planetary Interiors, v. 143-144, p. 255-269, doi: 10.1016/j.pepi.2003.09.015.

Poirier, J.P., 1982, On transformation plasticity: Journal of Geophysical Research, v. 87, p. 6791-6797.

Prakapenka, V.P., Shen, G., Dubrovinsky, L.S., Rivers, M.L., and Sutton, S.R., 2004, High pressure induced phase transformation of $\mathrm{SiO}_{2}$ and $\mathrm{GeO}_{2}$ : Difference and similarity: Journal of Physics and Chemistry of Solids, v. 65, p. 1537-1545, doi: 10.1016/j.jpcs.2003.12.019.

Rubie, D.C., and Ross, C.R., II, 1994, Kinetics of the olivine-spinel transformation in subducting lithosphere: Experimental constraints and implications for deep slab processes: Physics of the Earth and Planetary Interiors, v. 86, p. $223-241$.

Rubie, D.C., Webb, S.L., and Brearley-Adrian, J., 1990, Mechanisms and kinetics of the olivine-spinel transformation in subducting slabs: Eos (Transactions, American Geophysical Union), v. 71, p. 966.

Schilling, F.R., 1999, A transient technique to measure thermal diffusivity at elevated temperatures: European Journal of Mineralogy, v. 11, p. 1115-1124.

Schmidt, C., Bruhn, D., and Wirth, R., 2003, Experimental evidence of transformation plasticity in silicates: Minimum of creep strength in quartz: Earth and Planetary Science Letters, v. 205, p. 273-280, doi: 10.1016/ S0012-821X(02)01046-4.

Schreiber, E., Anderson, O.L., and Soga, N., 1973, Elastic Constants and Their Measurement: New York, McGraw-Hill, 196 p.

Schreyer, W., 1995, Ultradeep metamorphic rocks: The retrospective viewpoint: Journal of Geophysical Research, v. 100, p. 8353-8366, doi: 10.1029/94JB02912.

Shimomura, O., Yamaoka, S., Yagi, T., Wakatsuki, M., Tsuji, K., Fukunaga, O., Kawamura, H., Aoki, K., and Akimoto, S., 1984, Multianvil type X-ray 
apparatus for synchrotron radiation: Proceedings of Material Research Society Symposium Proceedings, v. 22, p. 17.

Shimomura, O., Yamaoka, S., Yagi, T., Wakatsuki, T., Tsuji, K., Fukunaga, O., Kawamura, H., Aoki, K., and Akimoto, S., 1985, Multi-anvil type high-pressure apparatus for synchrotron radiation, in Minomura, S., ed., Solid State Physics under Pressure: Recent Advance with Anvil Devices: Tokyo and Dordrecht, KTK Science Publishers, Tokyo and Reidel, p. 351-356.

Shimomura, O., Utsumi, W., Taniguchi, T., Kikegawa, T., and Nagashima, T., 1992, A new high-pressure and high-temperature apparatus with sintered diamond anvils for synchrotron radiation use, in Syono, Y., and Manghnani, M.H., eds., High-Pressure Research: Application to Earth and Planetary Sciences: Tokyo, Terra Scientific Publishing Company, p. 3-11.

Suzuki, A., Ohtani, E., Kondo, T., Kuribayashi, T., Niimura, N., Kurihara, K., and Chatake, T., 2001, Neutron diffraction study of hydrous phase G: Hydrogen in the lower mantle hydrous silicate, phase G: Geophysical Research Letters, v. 28, p. 3987-3990, doi: 10.1029/2001GL013260.

Tinker, D., Lesher, C.E., Baxter, G.M., Uchida, T., and Wang, Y., 2004, Highpressure viscosimetry of polymerized silicate melts and limitations of the Eyring equation: American Mineralogy, v. 89, p. 1701-1708.

Utsumi, W., Toyama, N., Endo, S., Fujita, F.E., and Shimomura, O., 1986, X-ray diffraction under ultrahigh pressure generated with sintered diamond anvils: Journal of Applied Physics, v. 60, p. 2201-2204, doi: $10.1063 / 1.337178$
Utsumi, W., Yagi, T., Leinenweber, K., Shimomura, O., and Taniguchi, T., 1992, High-pressure and high-temperature generation using sintered diamond anvils, in Syono, Y., and Manghnani, M.H., eds., High-Pressure Research: Application to Earth and Planetary Sciences: Tokyo, Terra Scientific Publishing Company, p. 37-42.

Yagi, T., 1988, MAX80: Large-volume high-pressure apparatus combined with synchrotron radiation: Eos (Transactions, American Geophysical Union), v. 69 , no. 12 , p. $18-27$.

Yagi, T., Akaogi, M., Shimomura, O., Suzuki, T., and Akimoto, S., 1987a, In situ observation of the olivine-spinel transformation in $\mathrm{Fe}_{2} \mathrm{SiO}_{4}$ using synchrotron radiation: Journal of Geophysical Research, v. 92, p. 6207.

Yagi, T., Akaogi, M., Shimomura, O., Tamai, H., and Akimoto, S., 1987b, High pressure and high temperature equations of state of majorite, in Manghnani, M.H., and Syono, Y., eds., High-Pressure Research in Mineral Physics: American Geophysical Union Geophysical Monograph 39, p. 141-147.

Zinn, P., Lauterjung, J., and Wirth, R., 1997a, Kinetic and microstructural studies of the crystallisation of coesite from quartz at high pressure: Physics of the Earth and Planetary Interiors, v. 212, p. 691-698

Zinn, P., Hinze, E., Lauterjung, J., and Wirth, R., 1997b, Kinetic and microstructural studies of the quartz-coesite phase transition: Physics and Chemistry of the Earth, v. 22, p. 105-111, doi: 10.1016/S0079-1946(97)00089-X.

Manuscript Accepted by the Society 14 August 2006 